\title{
Glucose sensors based on electrospun nanofibers: a review
}

\author{
Anitha Senthamizhan ${ }^{1} \cdot$ Brabu Balusamy $^{1} \cdot$ Tamer Uyar $^{1,2}$
}

Received: 15 July 2015 /Revised: 20 October 2015 / Accepted: 27 October 2015 / Published online: 14 November 2015

(C) Springer-Verlag Berlin Heidelberg 2015

\begin{abstract}
The worldwide increase in the number of people suffering from diabetes has been the driving force for the development of glucose sensors. The recent past has devised various approaches to formulate glucose sensors using various nanostructure materials. This review presents a combined survey of these various approaches, with emphasis on the current progress in the use of electrospun nanofibers and their composites. Outstanding characteristics of electrospun nanofibers, including high surface area, porosity, flexibility, cost effectiveness, and portable nature, make them a good choice for sensor applications. Particularly, their nature of possessing a high surface area makes them the right fit for large immobilization sites, resulting in increased interaction with analytes. Thus, these electrospun nanofiber-based glucose sensors present a number of advantages, including increased life time, which is greatly needed for practical applications. Taking all these facts into consideration, we have highlighted the latest significant developments in the field of glucose sensors across diverse approaches.
\end{abstract}

Published in the topical collection Fiber-based Platforms for Bioanalytics with guest editors Antje J. Baeumner and R. Kenneth Marcus.

Anitha Senthamizhan

senthamizhan@unam.bilkent.edu.tr

Brabu Balusamy

drbrabu@gmail.com

Tamer Uyar

uyar@unam.bilkent.edu.tr; tameruyar@gmail.com;

tamer@unam.bilkent.edu.tr

1 UNAM-National Nanotechnology Research Center, Bilkent University, Ankara 06800, Turkey

2 Institute of Materials Science and Nanotechnology, Bilkent University, Ankara 06800, Turkey
Keywords Biosensors · Nanofibers · Electrospinning · Glucose $\cdot$ Nanomaterials

\section{Introduction}

Owing to their vast range of application in the fields of medical diagnosis, diabetes management, bioprocess monitoring, food industries, and environmental monitoring, more attention has been given to the development of highly sensitive and selective glucose sensors [1-4]. Diabetes is considered to be a globally prevalent metabolic illness, which causes the blood glucose level to increase to $126 \mathrm{mg} / \mathrm{dL}$ or higher $(<100 \mathrm{mg} / \mathrm{dL}$ for the normal level according to American Diabetes Association) [5]. On a global basis, diabetes is said to affect 382 million people, and is expected to reach half a billion by the year 2035 [6]. The initiative for biosensors dates back to the 1960 s with the revolutionary study of Clark and Lyons, followed by the work of the first enzyme-based glucose sensor by Updike and Hicks in 1967 [7, 8]. These studies provided compelling evidence about the amount of oxygen consumed in the glucose oxidase (GOx)-catalyzed reaction of glucose oxidation. Consequently, extensive research has been undertaken, studying the various types of glucose sensors, including optical and electrochemical sensors [9-16]. Generally, glucose sensors can be broadly divided as GOx-based sensing (i.e., enzymatic glucose sensing) and nonenzymatic glucose sensing.

Enzymatic glucose detection involves the oxidation of glucose in the presence of GOx enzyme, which has been extensively utilized for constructing several sensors for glucose detection, mainly because of their high sensitivity and selectivity to glucose. For the fabrication of these sensors, immobilization of enzymes on a suitable matrix along with their stability is critical [17-19]. Nevertheless, these sensors 
involve highly complex procedures of immobilization and also display lack of long-term stability. In addition, the sensing abilities of these enzymes are very much prone to differences in $\mathrm{pH}$ and temperature during measurements, because of their nature. Thus, greater attention has been devoted for the development of nonenzymatic glucose sensors, suppressing the disadvantages of enzymatic biosensors. Whether enzymatic or nonenzymatic, the analytical performances can be largely increased by using unique nanostructure materials [20-38].

As a well-known fact, the morphology of nanomaterials in sensors has a vital part in determining their activity, selectivity, and stability in a catalytic process. Various studies from the literature have provided evidence that the exotic variety of these nanomaterials of different morphologies, including nanowires, nanospheres, nanosheets, nanofibers, and flowerlike nanostructures, have achieved enhanced performance in monitoring and detection of glucose [21-32]. Also, the stability of these nanoparticles has to be given equal importance and consideration, apart from controlling their size. In order to avoid the agglomeration of the nanomaterials, a robust support system has to be in place for the particles to maintain their individualistic characteristics. Interestingly, the fabrication of enzymes requires the immobilization of enzymes on solid interfaces, which can be obtained by various strategies, such as physical adsorption, covalent attachment, and physical entrapment or encapsulation, etc. Although progress is being made in the current scenario, some novel host materials, such as graphene, carbon nanotubes, ordered mesoporous silicabased materials, etc., are being utilized in glucose biosensors because of their large surface area and good biocompatibility [33-40]. Besides, the expenses involved in the reproducible production of nanomaterials and nanostructures are of high importance. Also, the unstable nature and loss of enzyme activity during immobilization process affects the thermal and chemical stability, sensitivity, and reproducibility of glucose sensors. Recent years have seen developing interest on colorimetry-based detection, which has several advantages, including high sensitivity, simplicity, and low cost [41-50]. A variety of fluorescent nanoparticles have been used as colorimetric probes [51-53]. Among various techniques, electrospinning is considered to be a facile and inexpensive technique for large-scale synthesis of nanofibers, characterized by exceptional length and uniform diameter ranging from tens of nanometers to several micrometers. Successful usage has been recorded for electrospun nanofibers and their composites in the fields of sensors, water purification, etc., because of their large surface area, flexibility, and porous structure [54-66]. These features of large surface area-tovolume ratio, high porosity, and interconnectivity of nanofibers prove them to be compelling for enzyme immobilization [67]. This is because the enzyme loading can be authentically increased, along with a significant decline in diffusion resistance of substrates.
To the best of our knowledge, not many reviews have reported on electrospun nanofibers-based glucose detection. Our review is one of the first to highlight the electrospinning approach and list its applications in various kinds of glucose sensors. The primary goal of our study is to provide the reader with a comprehensive understanding of the new advances in the field of electrospun nanofibers and their composites that can be used for increasing sensor performance. We are confident that such advances are vital for developing flexible and adaptable sensors, which will pave the path for new avenues and future research.

\section{Overview of glucose sensor development}

Including electrochemical, optical, and electromagnetic spectroscopy biosensors, numerous glucose biosensors have been studied and reported [68-78]. Considering the various approaches involved in glucose sensor, the mechanisms fall into two main categories: (1) enzymatic and (2) nonenzymatic, both of which have been intensively researched and utilized. The basic principle of enzymatic glucose detection is the oxidation of glucose in the presence of air by GOx enzyme, producing gluconic acid. Rightly described as the 'ideal enzyme' for glucose oxidation in the review by Wilson and Turner in 1992, these possess a relatively high selectivity, sensitivity, and stability compared with other enzymatic materials [76]. Starting back in the 1962 with the excellent work of Clark and Lyons [7], the first enzyme-based glucose sensor was initiated by Updike and Hicks in 1967 [8]. The conversion of electroinactive substrates to electroactive products with the utilization of enzymes is elaborated in the works of Clark's original patent of amperometric enzyme electrode [79].

Another enzyme used for glucose sensing is Glucose dehydrogenase (GDH), which is used for fabricating commercial test strips for blood glucose, owing to their ability to operate at lower detection potentials [80-84]. Also, hexokinase-based sensing is used as a reference system mainly for the detection of glucose in blood because of its ultrahigh specificity. However, hexokinase enzyme has not been in wide use in the research of glucose sensing as GOx, due to its high cost, lower stability, and the necessity for ATP in its enzymatic reaction $[80,85,86]$. Various strategies, including physical adsorption, covalent attachment, and physical entrapment or encapsulation have been used for the immobilization of enzymes on solid interfaces [87]. These enzymatic sensors, based on their glucose oxidation mechanisms, can be broadly classified into three generations. The summary of the entire glucose oxidation mechanism is displayed in Fig. 1.

In 1975, Yellow Spring Instrumentation Company devised the first commercial glucose sensor based on the first generation glucose biosensor, which is dependent on the presence of 


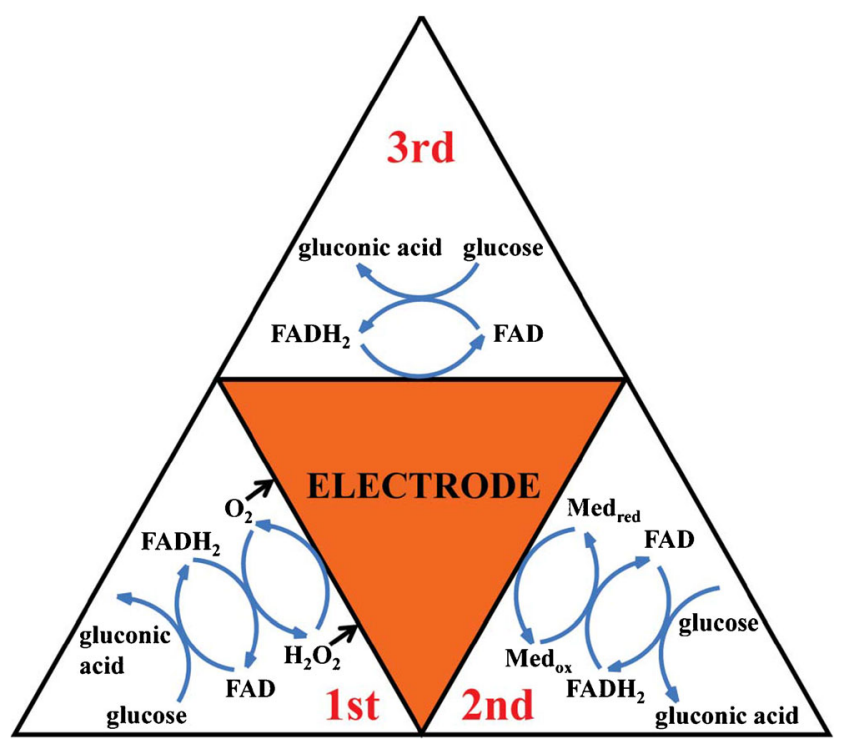

Fig. 1 Summary of enzymatic glucose oxidation mechanisms, presented as first, second, and third. [Reprinted with permission from [80] (C) 2013 Royal Society of Chemistry]

oxygen as a co-substrate [88]. However, these sensors experienced failure owing to issues regarding the presence of electroactive interference species in the blood and the dependence on free oxygen as a catalytic mediator. In order to overcome these defects, the second generation of sensors was initiated by the usage of synthetic electron accepting-mediators as alternative co-substrates. This included ferrocene derivatives, ferricyanide quinones, and transition-metal complexes [89-92]. Yet again, the second generation sensors also posed challenges because of their size and diffuse molecules. Also, it was difficult to maintain the mediator near the electrode and enzyme and the formation of interference species called hydrogen peroxide. This was followed by the use of third generation of sensors without employing any natural and synthetic electron mediators, facilitating the direct electron transfer between the enzyme and the electrode [88].

Nevertheless, there still remain some disadvantages of enzyme-based glucose determination. Although enzymatic sensors are highly selective, sensitive, fast, and reversible, their chemical and thermal instabilities originating from the intrinsic nature of enzymes as well as their tedious fabrication procedures and high cost prove them to be disadvantageous [88]. This was followed by the presence of complicated enzyme immobilization and critical operating conditions [93]. Also, the activity of enzymes is prone to be affected by external parameters, such as temperature, $\mathrm{pH}$, humidity, and toxic chemicals $[94,95]$. This has prompted various enzyme-free sensors to further investigate the electrocatalytic activity and selectivity towards glucose oxidation to address the issues associated with enzymatic sensors. It is to be noted here that the underlying principle of electrocatalysis is the adsorption of analytes to electrode surface.
In 1909, Walther Loeb reported the direct electro-oxidation of glucose to gluconic acid in a sulfuric acid solution at a lead anode [96]. Recent past has also observed the development of nonenzymatic glucose sensors by using several electrocatalysts in glucose oxidation. In general, these enzyme-free sensors are considered to be fourth generation sensors. However, the challenges posed in this approach include (1) the restriction in the sensitivity of glucose sensing because of the relatively low kinetics of glucose electrooxidation on conventional electrodes; (2) the impairment of noble metal electrodes by the irreversibly adsorbed oxidation intermediates of glucose and the adsorbed chloride ions, and (3) the poor selectivity of nonenzymatic glucose sensors, giving the possibility of oxidation of some other sugars and interfering species in the potential range of glucose oxidation $[80,97,98]$. This also includes the expensive nature of these sensors, fouling of electrodes and their instability, making them unfit for practical applications.

Recent years have seen continuous reports of nanomaterials based nonenzymatic glucose sensors, in spite of various challenges posed by enzymatic glucose sensors [99]. This also included the introduction of several types of nanostructured materials, such as metal nanoparticles (platinum [100], gold [101], palladium [102], nickel [103], copper [104]); metal oxides (copper oxide [105], cobalt oxide [106], nickel oxide [107], manganese oxide [108], zinc oxide [109], iron oxide [110]); metal complexes (nickel hexacyanoferrate [111]); alloys (platinum-Lead [112], platinum-ruthenium [113], platinum-iridium [114], platinum-nickel [115], platinum-gold [116], gold-silver [117], gold-ruthenium [118], gold-copper [119]), nickel oxide/carbon [120], platinum/nickel oxide [121], copper/nickel oxide [122], copper/zinc oxide [123], copper/copper oxide [124], palladium/copper oxide [125], titanium dioxide/copper oxide [126], cadmium oxide/nickel oxide [127]); quantum dots (cadmium telluride [128], zinc sulfide [129], cadmium sulfide [130]); polymers (polyaniline [131], $N$-isopropylacrylamide [132]); and carbon based materials (fullerene [133], carbon nanotubes and graphene [134], carbon nanofibers [135]). This review has concentrated solely on presenting the exclusive nature of electrospun nanofibers and their composites for the efficient development of glucose sensors.

\section{Electrospinning approach}

Electrospinning has been considered to be an effective method for the fabrication of nanofibers from a wide range of materials. Among the prominent ranges of materials, electrospinning produces nanofibers of polymers, composites, ceramics, and supramolecular structures [136-140]. The comprehensive understanding on the various parameters and processes involved for nanofiber formation permits us to fabricate the desired fiber assemblies. Technically, the process of 
electrospinning is defined as the uniaxial elongation of a jet, released from the charged polymer solution in the presence of a strong electric field. The factors affecting the diameter and morphology of the electrospun nanofibers are generally divided into two major categories; materials-related parameters (polymer type, molecular weight, solvent type, viscosity, solution conductivity, surface tension, etc.) and electrospinning process parameters (applied voltage, distance between electrodes, flow rate, nozzle diameter, collector type, etc.) [141-151]. The uniform and defect-free (bead-free) electrospun nanofibers display various features, including high surface area, coupled with excellent porosity, high structural and mechanical properties, flexibility, low basis weight, and cost effectiveness nature. The most compelling benefit in the entire electrospinning process is their efficiency to completely lace together a variety of functional molecules/ particles into a nanofibers matrix. Moreover, these functional molecules/particles either disperse into the polymer solution, followed by electrospinning them to produce composites in the form of continuous nanofibers (named in-situ approach) or attaching on the nanofibrous assemblies (named ex-situ approach). Both of the resulting products possess enhanced manufacturing capabilities and use a facile technique and carry remarkable flexibility [151-153]. The eminent feature of high flexibility aids in their easy handling and maintains their reproducibility. In order to obtain high sensitivity towards the analyte, the selection of substrate supporting effective loading of enzymes is essential. High-surface area, optimum porosity, and chemical inertness are some of the ideal features essential to obtain elevated performance for the sensors. Till now, several nanostructured materials have been used successfully as support matrix, including porous silica structures and nanoparticles; and also various approaches can be adopted for the immobilization of enzyme including physical adsorption, cross-linking, and self-assembly [154-156]. The nanoparticles usually limit the mass transfer rate and are also difficult to recycle. Out of different host materials, electrospun fibrous membrane proves to be efficient for achieving improved sensing performance because of its appealing feature of a large surface area and porous structure facilitating enhanced functionalization and high loading capacity, stability, and long life time of enzymes.

There has been great interest in the fabrication of electrospun metal oxide nanofibers and noble metal nanofibers for glucose detection, as these tend to form highly porous three-dimensional networks, possessing high conductivity, minimized diffusion resistance for analytes, and enhanced electron transfer. One of the simplest methods of incorporating glucose oxidase in the nanofibers is by mixing glucose oxidase into the solution, followed by the process of electrospinning, and subsequent change in the current has been noted following immersion of electrospun coated electrode into the glucose solution. A serious problem encountered in enzyme-based sensor is the loss of enzyme activity attributable to the change in the environmental parameters since the enzymes are used to denature under varying the $\mathrm{pH}$ values and temperature. Therefore, protecting the enzymes is of great importance in designing biosensors to enhance the performance. As we looked for further details in the literature, electrospun-based nanofibers and their composites proved to overcome the disadvantages confronted in previous investigations, thus enhancing the overall sensing performance of glucose $[29,36,157]$. This technique has elaborated the stability of the enzymes and their extended application. The following sections brief the importance of electrospun nanofiber based glucose sensing performance under several aspects. We extend our apologies to authors whose works have been unintentionally left out.

\section{Composite fibers}

Increasing attention has been devoted for the development of composite materials owing to their ability to combine the features of two components. Current applications have used unique properties of nanoparticles to be delivered as fillers of composites or as coating materials. It is the property of this polymer-nanoparticle composite that has enhanced the flexibility, stability, and the conformational ability for the formation of complicated structures, while retaining the nanoparticle traits [158-160]. While the polymer network serves as a template medium, it also acts as the stabilizing agent for the nanoparticles on a long-term basis and proves to be a landmark in protecting their usability and function. One of the key parameters that are responsible for enhancing the performance of the composites includes the uniform distribution of nanoparticles in the polymer matrix. Selectivity promoted by surface modification plays a major role for sensor application. However, due to the large specific surface energy, the nanoparticles have shown a tendency to aggregate $[161,162]$, resulting in unavoidable circumstances, as the nanoparticles start to distribute inhomogeneously in the polymer matrix, finally losing their function. Despite introducing several methods to prepare composites, challenges have been faced, including random distribution and aggregation of nanoparticles in polymer matrix.

Proving to be an attractive metal for the oxidation of glucose, the catalytic activity of gold $(\mathrm{Au})$ toward glucose oxidation is said to be increased by depositing Au nanoparticles on a supporting matrix $[163,164]$. This is evident in the works of $\mathrm{Li}$, C. et al., in 2012, where an enzymeless glucose biosensor based on polypyrrole nanofibers-supporting Au nanoparticles $(\mathrm{Au} / \mathrm{PPyNFs})$ is demonstrated [165]. Polypyrrole nanofibers (PPyNFs) have been considered as one of the leading conducting polymers and are widely used as a supporting matrix in electrochemical sensors. Their wide usage is attributed to good physical and electrical properties, excellent 
environment stability and biocompatibility, and ease of preparation. Considerable effort has been gained for the application of conducting polymer to bioelectronic surfaces to resolve the challenges posed by enzyme-based biosensors $[166,167]$. This has been made possible by increasing the signal-to-noise ratio and thereby serving as a suitable matrix for the immobilization and entrapment of enzymes.

The recent investigation has also supported the functional retaining of GOx post-entrapment in conducting polymers, and is found to be more resistant to denaturization towards changes in $\mathrm{pH}$ or temperature [168]. A new and novel approach was demonstrated by Yang G. et al., for the fabrication of enzyme entrapped conducting polymer nanofibers, thus offering higher sensitivity and increased life time compared with conducting polymer film counterparts [169]. Sufficient research has been done on the application of poly $(3,4-$ ethylenedioxythiophene) (PEDOT) in amperometric biosensors because of its higher chemical stability and electrical conductivity [170]. Figure 2a-e display the fabrication process of GOx-incorporated PEDOT on the microelectrode array. The process involves the electrodeposition of the GOx incorporated-PEDOT films (PEDOT F-GOx) onto the surface of platinum (Pt) microelectrode arrays by electropolymerization. Then, the poly(L-lactide) (PLLA) nanofibers were produced directly on Pt microelectrode arrays to obtain to obtain GOx incorporated-PEDOT nanofibers (PEDOT NFs-GOx). To obtain GOx-incorporated PEDOT nanofibers (PEDOT NFs-GOx), poly(L-lactide) (PLLA) nanofibers were first directly electrospun on Pt microelectrode arrays. Subsequently, electrochemical deposition of PEDOT on the Pt microelectrodes and around PLLA nanofibers was performed in a similar manner to the PEDOT F-GOx. Figure $2 \mathrm{~h}-\mathrm{m}$ display the optical and SEM images of Pt microelectrode arrays, PEDOT F-GOx, and PEDOT NFs-GOx on the Pt sites. The authors have highlighted four advantages of the designed sensor, which are the presence of nanoscale matrix for the entrapment of GOx, reduced impedance, increased entrapment of GOx within PEDOT, and detection of glucose at lower potential.

In the recent past, carbon-based nanoscale materials such as graphene [171], carbon nanofibers (CNFs) [172], carbon nanotubes (CNTs) [173], and carbon foam [174] to be used as immobilization matrix because of their strong electrocatalytic activity and minimization of surface fouling onto electrochemical devices has been explored. The immobilization of biomolecules onto the surface of electrospun carbon structures has seen the emergence of a new class of glucose sensors with improved performance characteristics. Liu Y. et al. demonstrated the nickel (Ni) nanoparticle-loaded carbon nanofiber paste (NiCFP) based nonenzymatic glucose sensor [175]. In this approach, the polyacrylonitrile (PAN)/Ni acetylacetonate (NiAA) composite fibers were prepared by using electrospinning method. Then, electrospun PAN/NiAA composite fibers were subjected to carbonization at highest temperature to obtain $\mathrm{Ni}$ loaded carbon nanofiber (diameter $200-400 \mathrm{~nm}$ ) nanocomposite. The SEM image of NiCF nanocomposite clearly confirmed the good distribution of Ni nanoparticles on the surface of the carbon nanofibers as demonstrated in Fig. 3A. It can be demonstrated from the TEM image that the nanoparticles, having a diameter of about 50 $\mathrm{nm}$, are embedded in the CF matrix, emphasizing the fact that they are not easily detachable from the NiCF nanocomposite (Fig. 3B). Thus, the NiCFP electrodes were prepared by mixing them with mineral oil. The prepared renewable NiCFP electrodes exhibited strong and quick amperometric response with detection limit of $1 \mu \mathrm{M}$, without being poisoned by chloride ions. The resulting response of the proposed glucose sensor was found to be highly sensitive and stable, which can be attributed to the electrocatalytic performance of the strongly embedded Ni nanoparticles on carbon fibers and their characteristics of chemical inertness.

Among the diverse advantages of electrospun nanofibers, their capacity to adapt to the variety of nanoparticles on their surface is noteworthy $[176,177]$. Recent studies by Li M. et al. demonstrated the nonenzymatic glucose detection based on series of bimetallic $\mathrm{MCo}(\mathrm{M}=\mathrm{Cu}, \mathrm{Fe}, \mathrm{Ni}$, and $\mathrm{Mn})$ nanoparticles anchored/embedded electrospun carbon nanofibers (CFs) [178]. The schematic representation of the preparation procedure for $\mathrm{CuCo}-\mathrm{CFs}$ and the comparison of their catalytic effect to other MCo-CFs are shown in Fig. 4. The various composites such as $\mathrm{Co}-\mathrm{CFs}$, $\mathrm{FeCo}-\mathrm{CFs}$, NiCo-CFs, and $\mathrm{MnCo}-\mathrm{CFs}$ were also prepared by following the same protocol. The observed results show the structural advantages of the 3-D network films and the synergistic effect of the $\mathrm{Co}$ (III)/ $\mathrm{Co}$ (IV) and $\mathrm{Cu}$ (II) $/ \mathrm{Cu}$ (III) redox couples, with the $\mathrm{CuCo}-\mathrm{CFs}$ displaying the best detection efficiency (sensitivity of $507 \mu \mathrm{A}$ $\mathrm{cm}^{-2} \mathrm{mM}^{-1}$, with a response time within $2 \mathrm{~s}$, a linear range from 0.02 to $11 \mathrm{mM}$ ), good reproducibility, and long-term stability. The outcome has shown that the catalytic abilities follow the order of $\mathrm{CuCo}-\mathrm{CFs}>\mathrm{FeCo}-\mathrm{CFs}>\mathrm{NiCo}-\mathrm{CFs}>$ $\mathrm{Co}-\mathrm{CFs}>\mathrm{MnCo}-\mathrm{CFs}$. It is notable that the high surface-tovolume ratio, complex pore structure, and extremely long length of electrospun $\mathrm{CuCo}-\mathrm{CFs}$ render the direct electrocatalytic oxidation and amperometric detection of glucose.

Uzun, S. D. et al. have successfully displayed an efficient surface design based on functional composite fibers for effective encapsulation of biomolecules [179]. The graphite rod electrode surfaces was first modified by coating with nylon 6,6 nanofibers and $4 \%(\mathrm{w} / \mathrm{w})$ multiwalled carbon nanotubes (MWCNTs), incorporating nylon 6,6 nanofibers (nylon 6,6/ 4MWCNT). Then, conductive polymer PBIBA (poly-4-(4,7di(thiophen-2-yl)-1H-benzo[d]imidazol-2-yl)benzaldehyde) was uniformly coated on nylon 6,6 and nylon 6,6/4MWCNT fibers to obtain a high electroactive surface as illustrated in Fig. 5a, b. The observed results confirmed the uniform coating of PBIBA all over the nanofiber surface, which might be the 
Fig. 2 Schematic of fabrication process of GOx-incorporated PEDOT on the microelectrode array: (a) Pt microelectrode array. (b), (c) Electrodeposition of GOxincorporated PEDOT film (PEDOT F-GOx). (c)

Electrospinning of PLLA nanofibers on the microelectrode array. (d), (f) Electrodeposition of PEDOT around the PLLA nanofibers to form GOxincorporated PEDOT nanofibers (PEDOT NF-GOx). (g)

Schematic of entrapment of GOx within PEDOT structure. (h) Optical micrograph of entire microelectrode array. (i) Optical micrograph of microfabricated electrodes showing two uncoated $\mathrm{Pt}$ sites and four GOxincorporated PEDOT sites. (j) Scanning electron micrograph of PEDOT F-GOx. (k) Higher magnification SEM of PEDOT FGOx. (I) Scanning electron micrograph of PEDOT NFs-GOx. (m) Higher magnification SEM of PEDOT NFs-GOx. [Reprinted with permission from [169] (C) 2014 WILEY-VCH Verlag $\mathrm{GmbH} \& \mathrm{Co}$. KGaA, Weinheim]
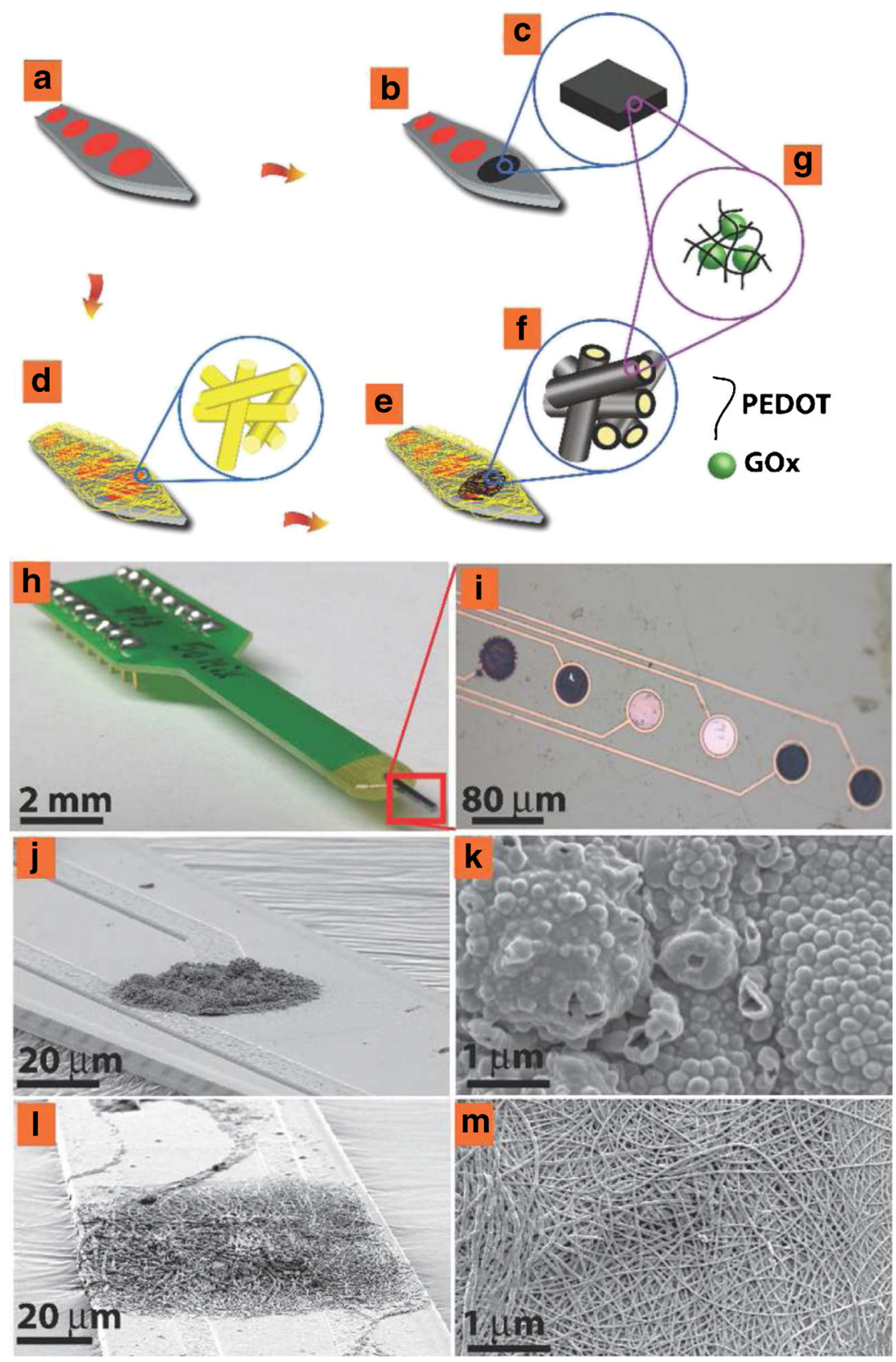

result of the porous morphology. The proposed surface design is expected to increase the surface area of the coated conducting polymer. The presence of aldehyde groups in polymeric structures facilitates the effective immobilization of glucose oxidase (GOx), considered to be a model enzyme by covalent binding. Owing to the rough structure of the surface, these enzyme molecules can easily penetrate into the polymeric layer. Thus, the most efficient, stable platform has been prepared by combining the PBIBA and nanofibers. This was due to the strong covalent bonds between GOx and nanofibrous composite coated surfaces. The produced glucose biosensors reveal good stability, promising $\mathrm{I}_{\max }$ values (10.03 and $16.67 \mu \mathrm{A}$ for nylon 6,6/PBIBA and nylon 6,6/4MWCNT/
PBIBA modified biosensors, respectively) and longer shelf life (32 and $44 \mathrm{~d}$ for nylon 6,6/PBIBA and nylon 6,6/ 4MWCNT/PBIBA modified biosensors, respectively).

Particular detailing has been provided to the direct electron transfer (DET)-based detection towards the advancement of mediator less biosensors (i.e., devices that do not want any extra reagents in a sample to detect the enzyme's substrate). This method, called the DET, occurs between the active redox enzymes and conductive nanomaterials, playing a critical role in developing electrochemical devices [180, 181]. As can be seen, if an enzyme that is immobilized on an electrode surface is found to be capable of DET and retain its bioactivity, it is utilized in sensors without adding mediators or promoters 
Fig. 3 SEM image (A), TEM image (B), and EDX spectra (C) of the NiCF nanocomposite. [Reprinted with permission from [175] (C) 2009 Elsevier B.V.]

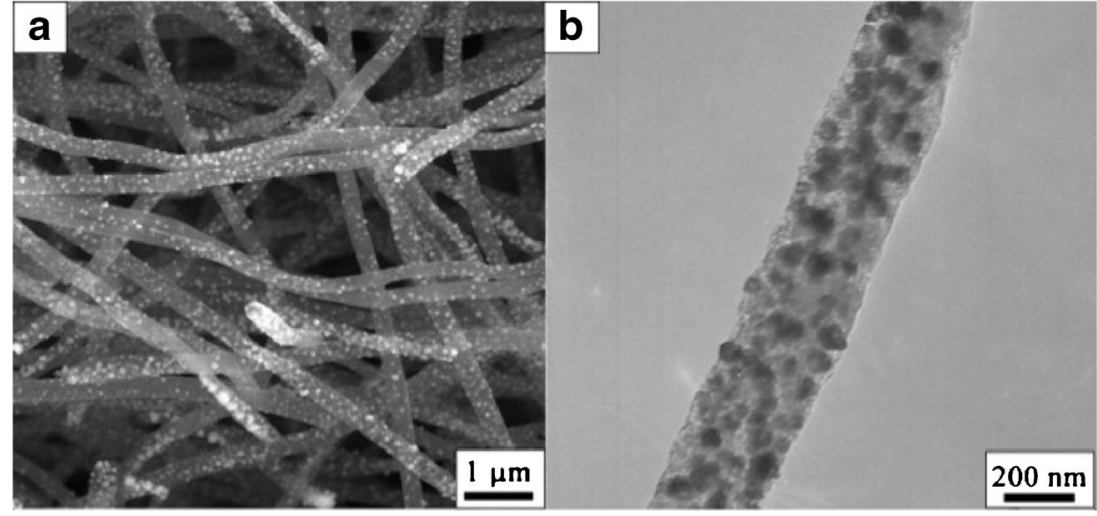

onto the electrode surface or into the solution. However, it is quite difficult for an enzyme to achieve a direct electrochemical reaction because of several factors. One would include denaturation of enzymes when they are adsorbed on the electrode surface, resulting in loss of their electrochemical activities and bioactivities. Secondly, the large 3-D structure of enzymes and the resulting inaccessibility of the redox centers prove them to be complex to get the desired DET between enzymes and electrode surfaces. Interestingly, much effort has been applied to devise solutions for the issues discussed above, resulting in varied degrees of success.

Zhang, X. et al. developed a DET-based glucose biosensor based on nitrogen-doped carbon nanospheres@carbon nanofiber (NCNSs@CNFs) composite [182]. The electrospun polypyrrole nanospheres doped polyacrylonitrile nanofibers (PPyNSs@PAN NFs) is subjected to thermal treatment to obtain NCNSs@CNFs. Thus, the as-prepared material can serve as an ideal substrate for the immobilization of GOx and realize the efficiency of DET of GOx without any pretreatment. Also, the mass diffusion of the matrices can be improved by the highly porous open structure of NCNSs@CNFs facilitating the DET between the active centers of GOx and the modified electrode. In the recent past, studies have determined that the change in the GOx structure was the underlying reason for the denaturation of GOx upon its absorption on the nanostructured surface and the subsequent loss of enzyme function. Interestingly, the observed results have highlighted the prominence of electrospun NCNSs@CNFs composite film to serve as a convincing platform for the construction of the DET based sensors.

\section{Metal oxide nanofibers}

As the properties of the substrate material prove to have a direct influence on the faradaic current of glucose oxidation, the selection of substrate electrode plays a critical role. Hence, nanostructured one-dimensional metal oxides such as zinc oxide, cobalt oxide, copper oxide, nickel oxide, manganese oxide etc. based glucose sensors have gained increased attention, owing to their large specific surface area, high electron mobility, chemical stability, electrochemical activity, and biocompatibility [43-48]. Several efforts have been successfully
Fig. 4 Synthesis of $\mathrm{CuCo}-\mathrm{CFs}$ hierarchical networks and their glucose detection performance. [Reprinted with permission from [178] C 2014 Elsevier B.V.]

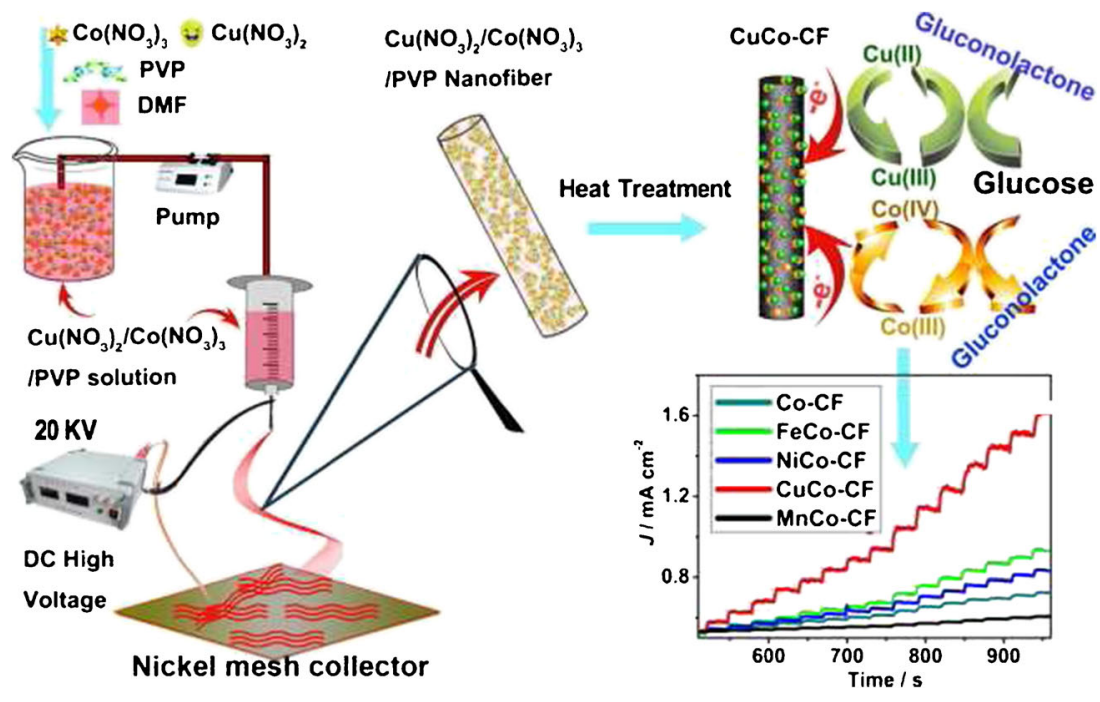


Fig. 5 Representative SEM images of (a) nylon 6,6/PBIBA and (b) nylon 6,6/4MWCNT/ PBIBA surfaces before GOx immobilization; (c) nylon 6,6/ PBIBA and (d) nylon 6,6/ 4MWCNT/PBIBA surfaces after GOx immobilization under optimized conditions. [Reprinted with permission from [179] (C) 2014 American Chemical Society]
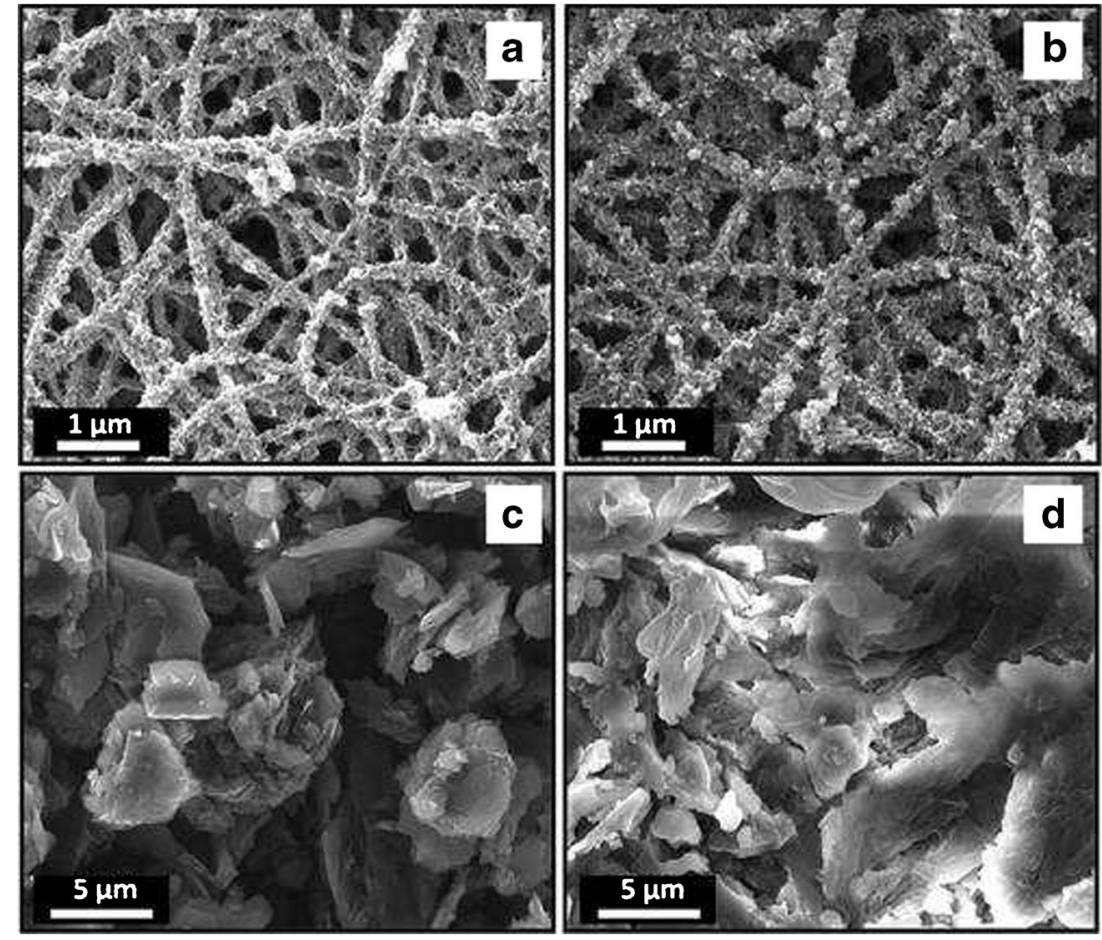

forwarded by various research groups for the efficient preparation of metal oxide nanofibers using electrospinning method. The resulting outcome emphasized the emergence of the electrospinning method to be a compelling technique for the construction of composite and inorganic nanofibers that has various applications including glucose sensor [183-197]. Metal oxide nanofibers are prepared in a two-step procedure (i.e., first the organic phase in composite nanofibers is removed via calcinations at high temperature). The key factors playing an important role in determining the morphology and properties of the metal oxide nanofiber include calcination temperature, heating rate, time, and environment. Recent studies and analyses have proven that the metal oxide nanofibers exhibit solid performance for the detection of glucose in the absence of enzymes.

Following this, the electrochemical properties of metal oxide nanofibers have been improved by incorporating several metals and nanoparticles $[28,198-200]$. Reported to be one of the most prominent materials, zinc oxide $(\mathrm{ZnO})$ nanofibers possess significant characteristics of biocompatibility, nontoxicity, stability, and electrochemical activities. A threedimensional network was devised by Zhou, C. et al. [201] consisting of $1 \mathrm{D} \mathrm{ZnO}-\mathrm{CuO}$ hierarchical nanocomposites (HNCs) and studied their enzymeless sensing properties by varying the thickness of three-dimensional network towards glucose. For a comparison study, pure $\mathrm{CuO}$ NWs and mixed $\mathrm{ZnO} / \mathrm{CuO} \mathrm{NWs}$ were also prepared by electrospinning. The resulting response of the nonenzymatic process towards glucose is as shown in Fig. 6. High demand has been observed for reducing the sensor to a single probe level due to it lower financial profit, high sensitivity with lower detection limit and faster response time.

Ahmad, M. et al. have successfully demonstrated a single $\mathrm{ZnO}$ nanofiber ( $\mathrm{ZnO}-\mathrm{NF}$ )-based highly sensitive amperometric glucose sensor [190]. In the study, the ZnO-NF was prepared by calcination of electrospun poly(vinyl pyrrolidone) (PVP)/zinc acetate composite fiber. The fabrication of single NF-based glucose sensor and its mechanism is illustrated in Fig. 7. First, using a high resolution microscope, the $\mathrm{ZnO}-\mathrm{NF}$ is transferred to a conventional gold electrode (with $3 \mathrm{~mm}$ diameter). This is followed by wetting the as-prepared $\mathrm{ZnO}$ $\mathrm{NF} /$ gold electrode by phosphate buffer (PB) solution and subsequent air drying for $2 \mathrm{~h}$. Since the $\mathrm{ZnO}-\mathrm{NF}$ is known to have poor adhesion towards the supporting materials, it is strongly expected to decrease sensitivity and selectivity over time. Thus, poly(vinyl alcohol) (PVA) solution is dropped onto the $\mathrm{ZnO}-\mathrm{NF} /$ gold electrode, followed by drying to form a film on the individual NF, after which GOx/L-Cys is added on the surface of the $\mathrm{ZnO}-\mathrm{NF} /$ gold electrode. Here, the washing step is adopted to remove the excess amount of adsorbed GOx on the surface of electrode. Thus, the altered electrode for glucose sensor is finally fabricated and obtained.

The sensing mechanism involves the oxidation of glucose by $\mathrm{GOx}(\mathrm{OX})$ to gluconolactone, while reduction of $\mathrm{GOx}(\mathrm{OX})$ takes place to form $\mathrm{GOx}(\mathrm{R})$. By reacting with the oxygen present in the solution, the consumed $\mathrm{GOx}(\mathrm{OX})$ could be regenerated from $\mathrm{GOx}(\mathrm{R})$. Consequently, hydrogen peroxide $\left(\mathrm{H}_{2} \mathrm{O}_{2}\right)$ production occurs in this process, which can be quantitatively detected on the modified electrode (please refer to equation in Fig. 7 a. 
Fig. 6 Reaction mechanism of $3 \mathrm{D}$ porous $\mathrm{ZnO}-\mathrm{CuO} \mathrm{HNCs}$ electrodes. [Reprinted with permission from [201] (C) 2014 Nature Publishing Group]

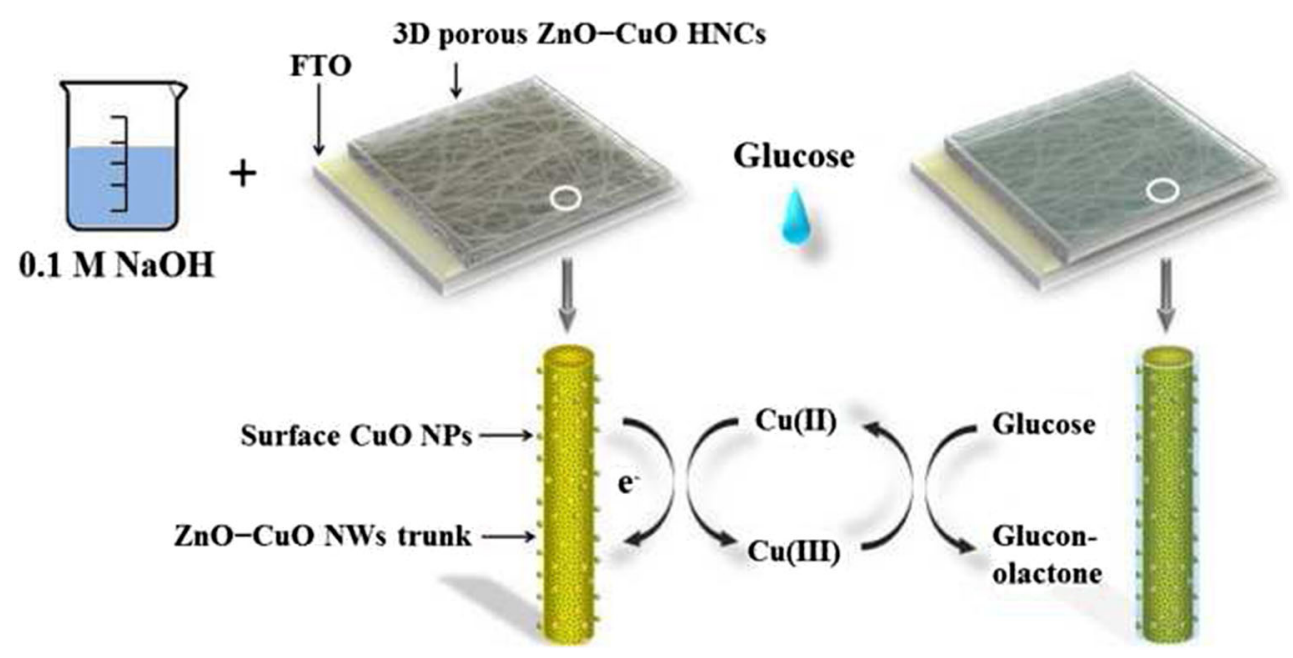

The cyclic voltammetric (CV) sweep curves of the bare (black line) and $\mathrm{ZnO}-\mathrm{NF}$-modified gold electrode without glucose (dotted line) and with $100 \mu \mathrm{M}$ glucose (red line) at the scan rate of $100 \mathrm{mVs}^{-1}$ in the range -0.4 to $0.8 \mathrm{~V}$ is clearly displayed in Fig. 7b. In contrast to the bare and modified electrode without glucose, there is significant increase in the oxidation current, relating to the oxidation of glucose by GOx catalysis. Additional attention is required for the stability of the nanofibers morphology because of the damaging property of the metal oxide nanofiber when being transferred on the electrode. Also, critical factors such as calcination, temperature, heating rate, and environment play vital roles in proving the properties of the nanofibers. Interestingly, two major events were observed during the calcination of composite nanofibers; the escapist attitude of polymers after decomposition and the crystallization of the metal oxide nanoparticles [202].

In general, the process of electrode preparation involves the dispersion of metal oxide nanofibers in suitable solvents by using the process of ultrasonication, followed by casting the suspension to the electrode surface to immobilize metal oxide nanofibers. In addition to the challenge of being time-consuming, this process also was found to affect the morphology [203]. An efficient method was demonstrated by Liu, G.
Fig. 7 (a) Schematic

presentation of the modified gold electrode and the mechanism of the glucose sensing on the modified electrode. (b) Cyclic voltammograms of the bare and modified gold electrode without and with $100 \mu \mathrm{M}$ glucose in $\mathrm{pH}$ 7.0 PB solution. (c) Cyclic voltammograms of the biosensor in PB solution ( $\mathrm{pH}$ 7.0) containing $100 \mu \mathrm{M}$ glucose at a scan rate of (a) $100 \mathrm{mV}$, (b) 80, (c) 50 , and (d) $20 \mathrm{mVs}^{-1}$. [Reprinted with permission from [190]. (C) 2010 American Chemical Society] a
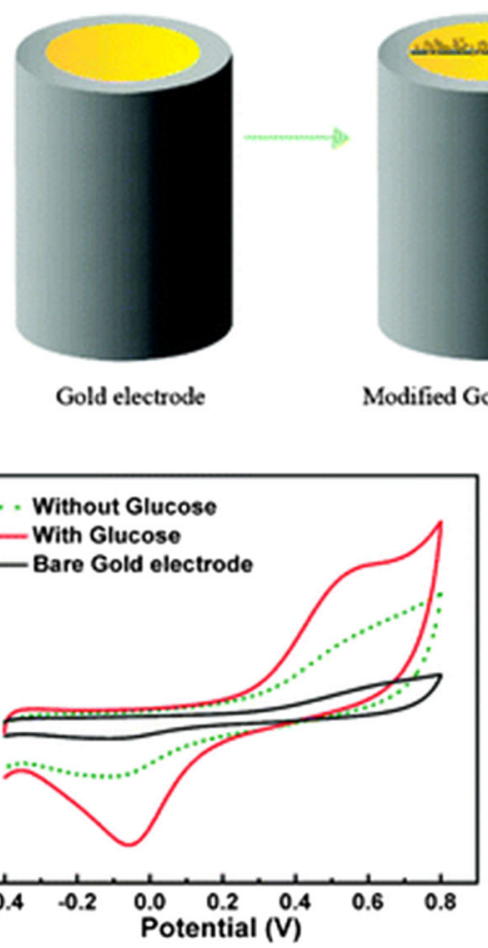

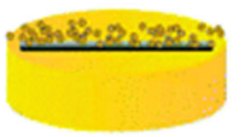

L. Cystein/Gox/PVA $\mathrm{ZnO}-\mathrm{NF} /$ Gold electrode

Glucose $+\mathrm{GO}_{\mathrm{x}}(\mathrm{OX}) \rightarrow$ Gluconolactone $+\mathrm{GO}_{\mathrm{x}}(\mathrm{R})$ $\mathrm{GO}_{\mathrm{x}}(\mathrm{R})+\mathrm{O}_{2} \rightarrow \mathrm{GO}_{\mathrm{x}}(\mathrm{OX})+\mathrm{H}_{2} \mathrm{O}_{2}$

b

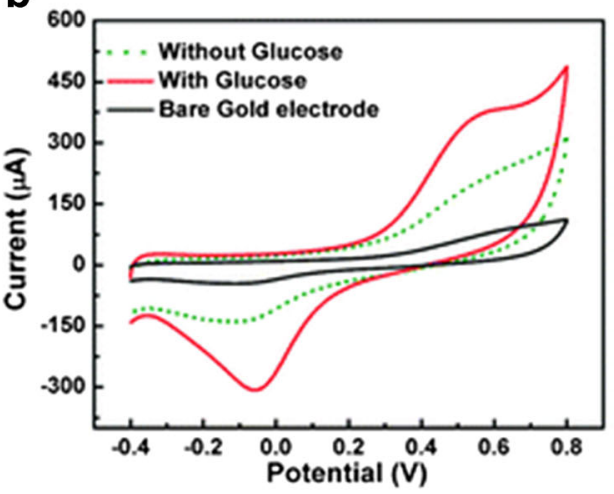

$\mathrm{H}_{2} \mathrm{O}_{2} \rightarrow \mathrm{O}_{2}+2 \mathrm{H}^{+}+2 \mathrm{e}^{-}$

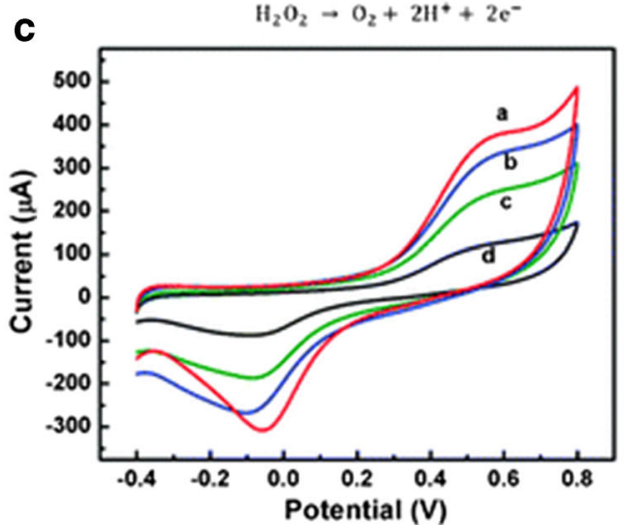


et al. for enhancing the stability and sensing performances of $\mathrm{CuO}$ NFs-ITO nonenzymatic glucose sensors, based on in situ electrospun fiber [204].

First, the precursor solution with $\mathrm{Cu}\left(\mathrm{NO}_{3}\right)_{2}$ dissolved in poly(vinyl pyrrolidone) (PVP) was subjected to direct electrospinning on an indium tinoxide (ITO) surface. Then, calcination was performed in air to remove the matrix polymer of PVP and subsequently convert the precursor fibers into $\mathrm{CuO}$ nanofibers. Electrode preparation by this technique was found to be simple, convenient, and, most importantly, ensured fast electron transfer between the $\mathrm{CuO}$ nanofibers and the ITO electrode, which improved the overall sensitivity of the sensor towards glucose. Since the $\mathrm{CuO}$ nanofibers on the ITO surface possess high stability and faster response towards glucose, it is convenient to directly use them as a working electrode for detection of glucose.

Furthermore, research has been directed towards the enhancement of sensing performance by using synergistic effects of two components. It has been observed that the immobilization of metal nanoparticles onto the metal oxide nanofibers increases the sensitivity of the sensor. The fabrication of silver nanoparticles modified cupric oxide nanofibers $(\mathrm{Ag} /$ $\mathrm{CuO} \mathrm{NFs}$ ) for nonenzymatic glucose sensors has been performed by Zheng, B. et al. [189]. Figure 8 schematically describes the preparation process for $\mathrm{Ag} / \mathrm{CuO} \mathrm{NFs}$ on ITO electrodes. Interestingly, it has been found that the response time is faster than the enzyme-based glucose sensor because of its direct deposition of electrospun NFs on the ITO electrode surface. Although there exists a narrow linear working range as seen in Fig. 9D, the sensitivity of the $\mathrm{Ag} / \mathrm{CuO}$ NFs-ITO towards glucose at $0.50 \mathrm{~V}$ is about 2.4-fold higher than the $\mathrm{CuO}$ NFs-ITO. The resulting outcomes stress the enhancement of sensor sensitivity by the incorporation of AgNPs into $\mathrm{CuO}$ NFs. The underlying reason behind the mechanism is that AgNPs not only improve the electron transfer between the $\mathrm{Ag} / \mathrm{CuO}$ hybrid NFs and the ITO electrode but also between the $\mathrm{Ag} / \mathrm{CuO} \mathrm{NFs}$ and the glucose molecules present in the solution.

Recent reports have shown that the well-defined porous nanostructures are proven to be ideal electrode materials towards glucose oxidation as they possess larger surface area, high porosity, and open geometry, reinforcing the mass and electron transport of electrolytes at the electrode-electrolyte interface. Three different kinds of electrospin-based nanofibers (NiO-Ag nanofibers, $\mathrm{NiO}$ nanofibers, and porous $\mathrm{Ag}$ ) have been prepared by Ding, Y. et al. [198]. The preparation method is a two-step procedure that involves the electrospinning of $\mathrm{Ni}\left(\mathrm{NO}_{3}\right)_{2}-\mathrm{AgNO}_{3}-\mathrm{PVP}, \mathrm{Ni}\left(\mathrm{NO}_{3}\right)_{2}-\mathrm{PVP}$, and $\mathrm{AgNO}_{3}-\mathrm{PVP}$ precursor nanofibers and a subsequent calcination process as described earlier.

In order to investigate the potential application of the prepared nanofibers in nonenzymatic glucose sensing, a comparative study has been performed. Subsequent results highlight the improved electrocatalytic property towards glucose electro-oxidation for $\mathrm{NiO}-\mathrm{Ag}$ hybrid nanofibers, compared with pure NiO nanofibers or porous Ag. For successful application in sensors, selectivity is as challenging as important to nonenzymatic glucose sensors because of the coexistence of the oxidative species such as ascorbic acid (AA) and uric acid (UA) with glucose in human blood, and the lack of such selectivity is a major drawback in nonenzymatic glucose sensors. The response of the porous $\mathrm{Ag} / \mathrm{GCE}$ to $0.125 \mathrm{mM} \mathrm{AA}$ and $0.33 \mathrm{mM} \mathrm{UA}$ is shown in Fig 10A, which clearly indicates the porous $\mathrm{Ag} / \mathrm{GCE}$ exhibited 17-fold and 55-fold higher
Fig. 8 The preparation process of $\mathrm{Ag} / \mathrm{CuO}$ NFs-ITO electrode. [Reprinted with permission from [189] (C) 2014 Elsevier B.V.]

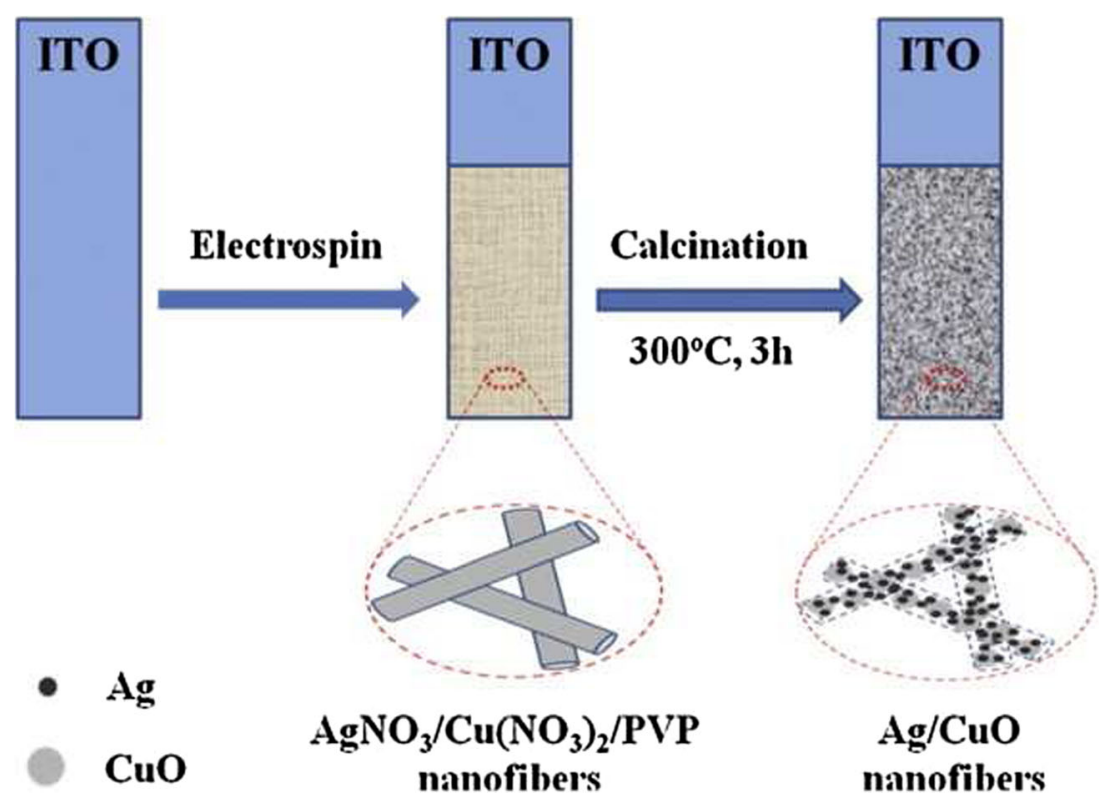


Fig. 9 (A) Effect of applied potential on the sensitivity of $\mathrm{Ag} /$ $\mathrm{CuO}$ NFs-ITO and $\mathrm{CuO} \mathrm{NFs}_{-}-$ ITO electrodes to glucose. (B) Nyquist plots of $\mathrm{Ag} / \mathrm{CuO} \mathrm{NFs}-$ ITO and $\mathrm{CuO}$ NFs-ITO electrodes in $0.10 \mathrm{M} \mathrm{KCl}$ solution containing $5.0 \mathrm{mM}[\mathrm{Fe}(\mathrm{CN}) 6] 3-/$ 4- redox couple. (C) Amperometric response of $\mathrm{Ag} / \mathrm{CuO} \mathrm{NFs}-$ ITO and $\mathrm{CuO}$ NFs-ITO to successive additions of glucose at an applied potential of $0.50 \mathrm{~V}$. (D) Calibration curves obtained from (C). Red and black lines are Ag/ $\mathrm{CuO}$ NFs-ITO and CuO NFsITO electrode, respectively. (The preparation process of $\mathrm{Ag} / \mathrm{CuO}$ NFs-ITO electrode. [Reprinted with permission from [189] (C) 2014 Elsevier B.V.)]
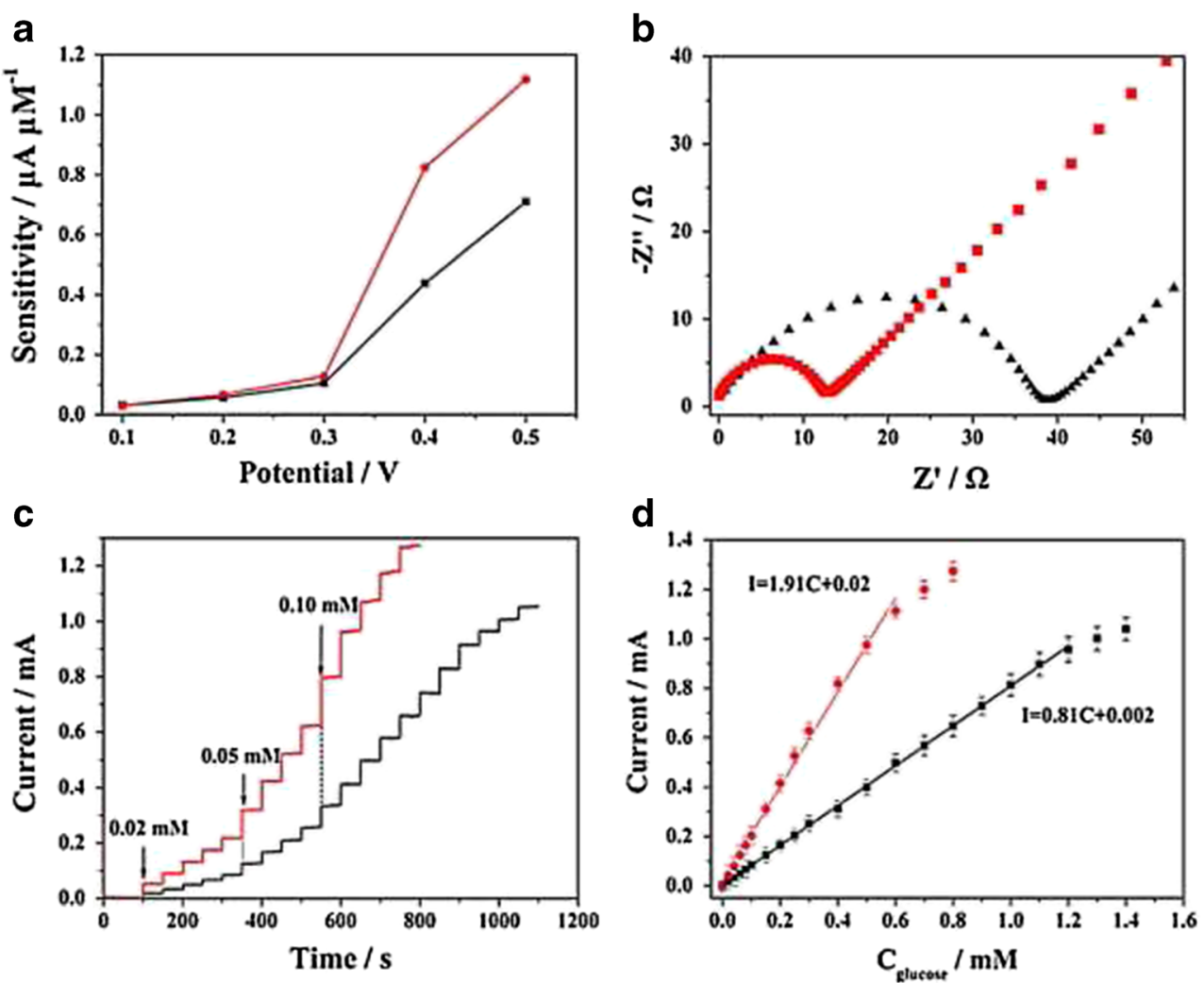

response than that of $4 \mathrm{mM}$ glucose at $0.1 \mathrm{~V}$. Better explanation can be offered by the catalytic activity of porous $\mathrm{Ag}$ towards AA and UA oxidation.

\section{Colorimetric detection}

Over the past few decades, remarkable advancement has been achieved in the development of glucose sensors by taking the benefits of huge number of several nanostructured materials. Most of the efficient analytical tests are time-consuming, require complicated data-collection and processing procedures, and involve sophisticated scientific instruments and professional operators. These procedures turn out to be expensive and thereby limit their extensive application. Among these methods, the colorimetric approach proves to be promising in addressing all these issues with ease, attributed to its low cost, simplicity, and practicality. This method proves to be advantageous such that the color change occurring in the presence of analytes can be read out by the naked eye without the need for any sophisticated instrument. The resulting features of the colorimetric sensor provide more comfort for field analysis and point-of-care diagnosis [205-209]. Recent past has observed the study of several fluorescent probes and their colorimetric sensing performance in various analytes such as toxic metal pollutant and explosives [210-212].

Furthermore, other varieties of solid matrices have also been successfully adopted to integrate the fluorescent probes, thereby improving the overall sensor performance for field applications [213-216]. The resulting solid support proves to be an ideal platform to retain their stability against varied atmosphere conditions and also provide easy accessibility to probe analytes. Nevertheless, many of the selected supports do not meet the demands, and persistently affect the reactivity and sensitivity of the sensor performance. Although sufficient selectivity and high sensitivity are obtained with these enzymatic sensors, the disadvantages, including chemical and thermal instabilities originating from the intrinsic nature of enzymes and complicated fabrication procedures, limit their analytical applications. Interestingly, electrospun nanofibers prove to dismiss all these detriments owing to their large surface area and excellent flexibility. This section focuses on the various developments in the field of colorimetric sensing using electrospun nanofibers.

$\mathrm{Ji}$, X. et al. have demonstrated a novel "ready-to-use" glucose test strip based on a polyurethane hollow nanofiber membrane by utilizing two commonly used chromogenic agents, 2 , 2'-azinobis-(3-ethylbenzthiazoline-6-sulphonate) and $o$ dianisidine as probes [217]. A coaxial electrospinning procedure has been set up to prepare the hollow nanofiber membrane-based testing strips for glucose measurement. A schematic illustration of the set-up for coaxial electrospinning and the reaction mechanism of the bi-enzyme system for glucose detection are shown in Fig. 11. For colorimetric detection, glucose oxidase (GOD), horseradish peroxidase (HRP), 


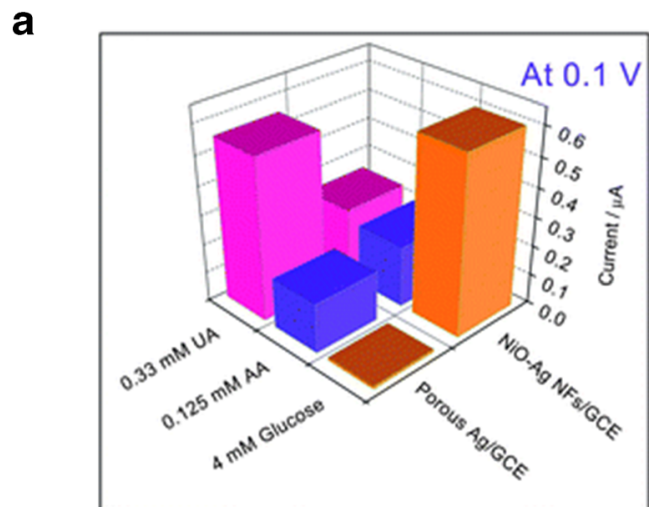

b

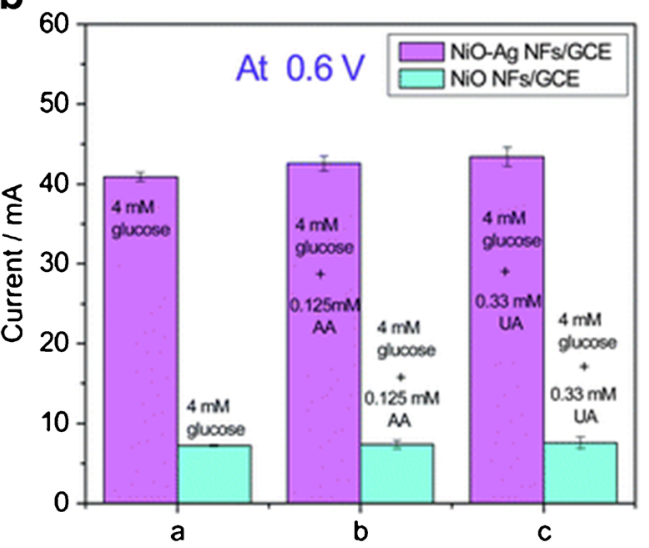

Fig. 10 (A) The response of the porous Ag/GCE and the NiO-Ag NFs/ GCE to the addition of $4 \mathrm{mM}$ glucose, $0.125 \mathrm{mM} \mathrm{AA}$, and $0.33 \mathrm{mM} \mathrm{UA}$ in $0.1 \mathrm{M} \mathrm{NaOH}$ at an applied potential of $0.1 \mathrm{~V}$; (B) the response of the $\mathrm{NiO} \mathrm{NFs} / \mathrm{GCE}$ and the NiO-Ag NFs/GCE to the addition of $4 \mathrm{mM}$ glucose, $4 \mathrm{mM}$ glucose with $0.125 \mathrm{mM} \mathrm{AA}$, and $4 \mathrm{mM}$ glucose with $0.33 \mathrm{mM}$ UA in $0.1 \mathrm{M} \mathrm{NaOH}$ at an applied potential of $0.6 \mathrm{~V}$. [Reprinted with permission from [198] (C) 2010 Royal Society of Chemistry)]

and chromogenic agent (ABTS or $o$-dianisidine) coimmobilized as a spun hollow nanofiber membrane was immersed in different concentrations of glucose solution $(1 \mathrm{~mL})$ prepared using PBS buffer ( $\mathrm{pH} 7.0,50 \mathrm{mM})$. Similarly, a control test was performed with blank hollow nanofibers that have no enzymes and chromogenic agent. At first, small round-shaped sensor strips in the diameter of $10 \mathrm{~mm}$ were prepared by cutting hollow nanofiber membranes immobilized with GOD, HRP, and $o$-dianisidine, and then $10 \mu \mathrm{L}$ of glucose solutions at varied concentrations were added onto the sensor strips. The prepared test strips can be operated in "dip-and-read" mode as an optical biosensor because of their unique "all-in-one" feature.

The visual colorimetric detection of test strips upon the addition of $10 \mu \mathrm{L}$ glucose samples of different concentrations is shown in Fig. 12. A quick formation of rufous color spot was noticed on the surface of the $o$-dianisidine-test strip following addition and the maximum intensity of the color reached at about $30 \mathrm{~s}$, and further it was stable for $10 \mathrm{~min}$. Notably, the increases in color intensity correspond to the increase in glucose concentration. As can be seen from Fig. 12B, an excellent correlation between the DR and glucose concentration was obtained in the range of $0.1-50 \mathrm{mM}$ with a regression correlation coefficient of 0.999 . The developed test strips also demonstrated excellent long-term storage stability. The prepared test strips are suitable for practical clinic applications because of their broad detection range and excellent stability. Furthermore, the simplicity in hollow nanofiber membrane preparation and also the advantages in simultaneous in situ co-immobilization of multiple substances pave a way for the development of a great variety of biosensors possessing multienzymes and coenzymes or chromogenic agents for measurement.

Due to large stokes shift, strong photostability, high quantum efficiency, and high oxygen quenching efficiency, luminescent transition-metal complexes have been widely used for fabricating optical oxygen biosensors and glucose biosensors. Zhou, C. et al. developed a fast and sensitive glucose sensor using iridium complex-doped polystyrene electrospun optical fibrous membrane (EOF) [218]. Iridium(III) bis(2phenylbenzothiozolatoN,C2') acetylacetonate [(bt)2Ir(acac)] was used as luminescence probe. The fibrous membrane was fabricated using a one-step electrospinning technique and further functionalized with glucose oxidases (GOD/EOF). The SEM image in Fig. 14A shows that the obtained EOF exhibits a porous fibrous membrane and its fibers are evenly and randomly distributed. The average diameter of the fiber was $\sim 1.4$ $\mu \mathrm{m}$, which was calculated from 65 diameter values of randomly selected fibers. Due to the presence of doped iridium complex, the fibrous membrane emitted yellow luminescence $(562 \mathrm{~nm})$ when excited at $405 \mathrm{~nm}$ (Fig. 14B).

Solvent compatibility is an important criterion for making composite luminescent probe for sensing. DMF $\left(N, N^{\prime}-\right.$ dimethylformamide) was selected owing to its remarkable disperse capability for (bt)2Ir(acac). Thus, to avoid the selfquenching and leaching effects during the luminescent measurements, the (bt)2Ir(acac) molecules can be uniformly and stably doped within the PS matrix. Glucose oxidase (GOD)/ EOF was prepared by covalently immobilizing GOD on the surface of EOF by using UV irradiation and glutaraldehyde cross-linking, which was further used for detection of glucose. Owing to the large surface area of the GOD/EOF, a large amount of immobilized GOD, efficient GOD biocatalyst reaction, and efficient oxygen quenching, high sensitivity and specificity and a quick response time in glucose detection can be attained. The schematic illustration of the GOD/EOF quickly detecting glucose is depicted in Fig. 13. The GOD/ EOF's luminescence intensity was greatly increased following addition of glucose and reached a stable value within $1 \mathrm{~s}$ as illustrated in Fig. 14C.

The underlying reason for the fibrous membrane with a high surface-to-volume ratio and a porous structure, diffuse efficiency of both the glucose and oxygen molecules into the 


$$
\begin{aligned}
& \mathrm{O}_{2}+\beta \text {-D-Glucose }+\mathrm{H}_{2} \mathrm{O} \stackrel{\mathrm{GOD}}{\longrightarrow} \beta \text {-D-Glucose- } \delta \text {-lactone }+\mathrm{H}_{2} \mathrm{O}_{2}
\end{aligned}
$$

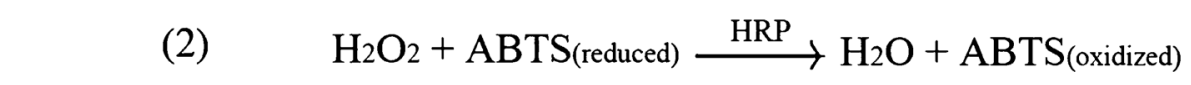$$
\mathrm{OR} \mathrm{H}_{2} \mathrm{O}_{2}+\text { o-Dianisidine(reduced) } \stackrel{\mathrm{HRP}}{\longrightarrow} \mathrm{H}_{2} \mathrm{O}+\text { o-Dianisidine(oxidized) }
$$

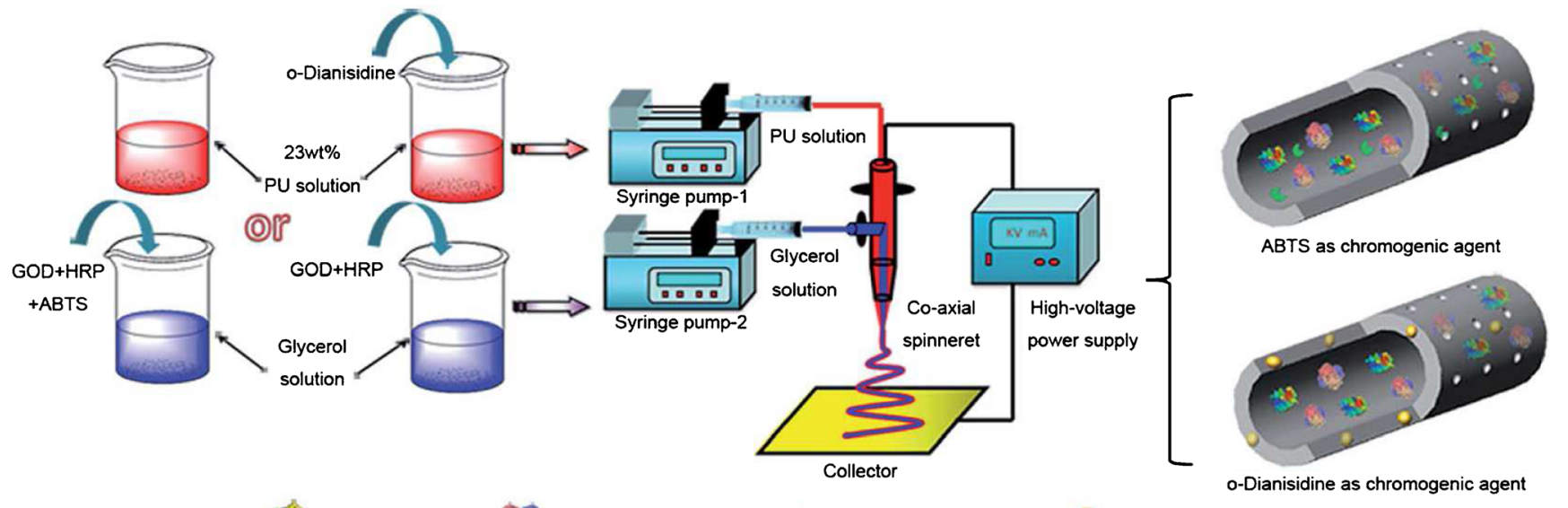

GOD

Fig. 11 Schematic illustrations of the bi-enzyme reaction for glucose measurement and the setup for coaxial electrospinning to prepare hollow nanofiber membrane-based glucose testing strips. During coaxial electrospinning, GOD, HRP, and chromogenic agent (ABTS or

EOF interior could be enhanced, as well as a fast electron or energy transfer between the fibers and dissolved oxygen could be realized. As shown in Fig. 14D, at the same level of glucose concentrations, the GOD/EOF by irradiation has higher luminescence intensity compared with that without irradiation. It was demonstrated that these irradiated PS fibers can be used as an effective biosensor support matrix for fabricating biosensors.

The detection limit was of $1.0 \times 10^{-10} \mathrm{M}(\mathrm{S} / \mathrm{N}=3)$, superior to that of reported glucose biosensor with $1.2 \times 10^{-10} \mathrm{M}$. It has been found that in diabetic patients, in vivo glucose

\section{ABTS}

odianisidine) were simultaneously immobilized in situ in the hollow nanofiber membrane. [Reprinted with permission from [217] (C) 2014 Royal Society of Chemistry]

monitoring permits continuous glucose monitoring and facilitates intensive control of blood glucose concentrations [219-221]. One of the first applications for such a device was demonstrated by Shichiri et al. in 1982 [222]. For the current scenario, challenges posed by these systems include long-term stability, inflammatory, biofouling, calibration, and selectivity. Also, it has been found that the stability of the implantable sensors reduce the frequency of implantation and replacement, thus resulting in long-term in vivo glucose monitoring with less effort by patients and less tissue damage. This designs the ideal sensor, supporting minimum

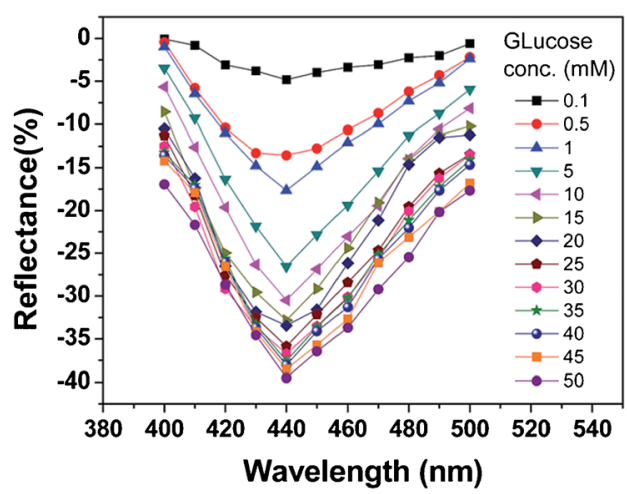

Fig. 12 Optimal detection of glucose by measuring the color intensity changes on the testing strip with $o$-dianisidine as chromogenic agent. (A) Differential reflectance spectra of the membrane test strips upon reaction with glucose solutions of different concentrations for $30 \mathrm{~s}$. (B) Correlation between the $\Delta \mathrm{R}$ of test strips and the log of glucose concentration. The

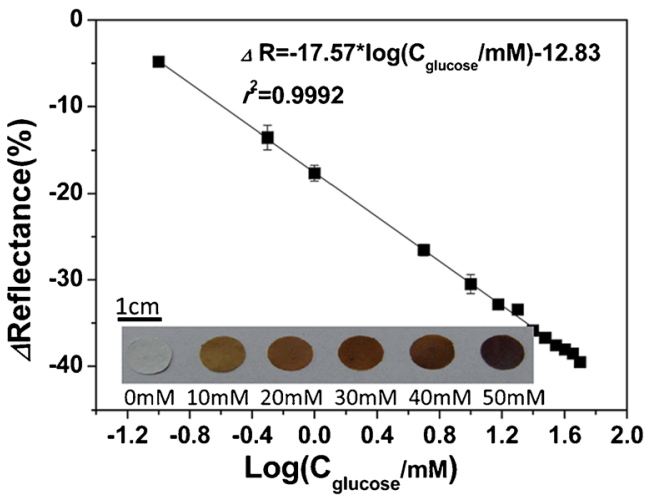

inset picture demonstrates the visual color change in response to the change in glucose concentration of the $o$-dianisidine test strip. The diameter of the membrane is $1 \mathrm{~cm}$. [Reprinted with permission from [217] (C) 2014 Royal Society of Chemistry] 
Fig. 13 Schematic illustration of the GOD/EOF quickly detecting glucose [Reprinted with permission from [218] (C) 2013, American Chemical Society]

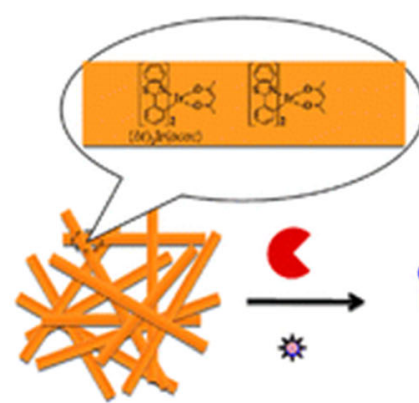

optical fibrous membrane

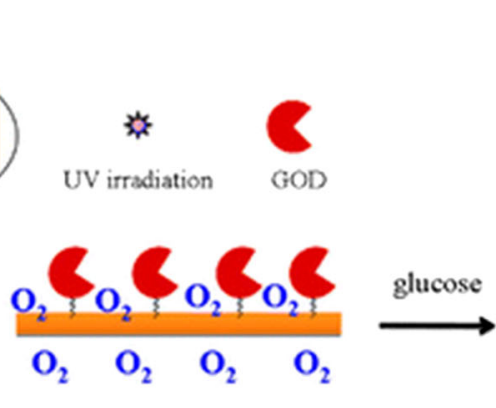

Weak luminescence

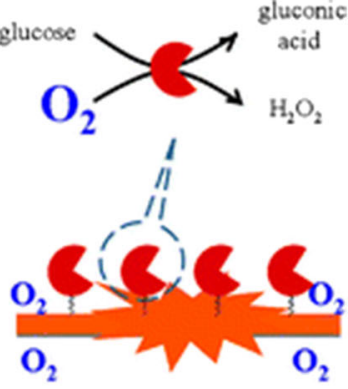

Strong luminescence replacement, thereby bringing in vivo sensor closer to practical implementation. However, the complete potentiality of long-term in vivo glucose monitoring is yet to be fully explored and realized as current fluorescence-based sensors cannot be maintained at an implantation site and their response to blood glucose concentrations over an extended period.

Although several nanosensors have been devised for in vivo glucose monitoring, their limited residence time at the site of injection proves to be challenging. Still, it has been found that the in vivo experiments show the ability of the fluorescent glucose-responsive sensors to track changes in glucose levels for up to $1 \mathrm{~h}$. These issues have been addressed by immobilizing sensors within gels, microworms, etc. The microworm-based fluorescent sodium sensor was developed by Ozaydin-Ince, G. et al., and has been used for monitoring the sodium concentration in vivo after subcutaneous injection [223].

Interestingly, it was evaluated that gel immobilization enhanced sensor residence time at the injection site over the course of $1 \mathrm{~h}$ [224-226]. However, it does not sustain its long life for sensor migration because of the small size of nanosensors to diffuse out of the gels. Yet, the functionality of a sensor to efficiently sustain for a longer time under physiological conditions is highly desirable. Literature shows evidence about the ability of boronic acids to irreversibly bind to glucose under physiological conditions. The first scientific study on this was reported by Yoon and Czarnik using anthracenyl boronic acid, which produced a measurable change in fluorescent intensity upon binding to glucose in solution [227].
Fig. 14 SEM image (A) and luminescence microscopy image (B) of the EOF. The inset shows the diameter distribution of the EOF. The fast response (C) of the EOF when the concentration of the added glucose increases from $1.7 \times 10^{-9} \mathrm{M}$ to $4.4 \times 10^{-9} \mathrm{M}$. Effects of UV irradiation and GOD amount (D) in a $1.0 \mathrm{mM}$ glucose solution. Each data was obtained from an average value of three replicate measurements. All relative standard derivation was less than $3.0 \%(\mathrm{n}=3)$. $\mathrm{pH} 7.0$ PBS buffers. [Reprinted with permission from [218] (C) 2013, American Chemical Society]
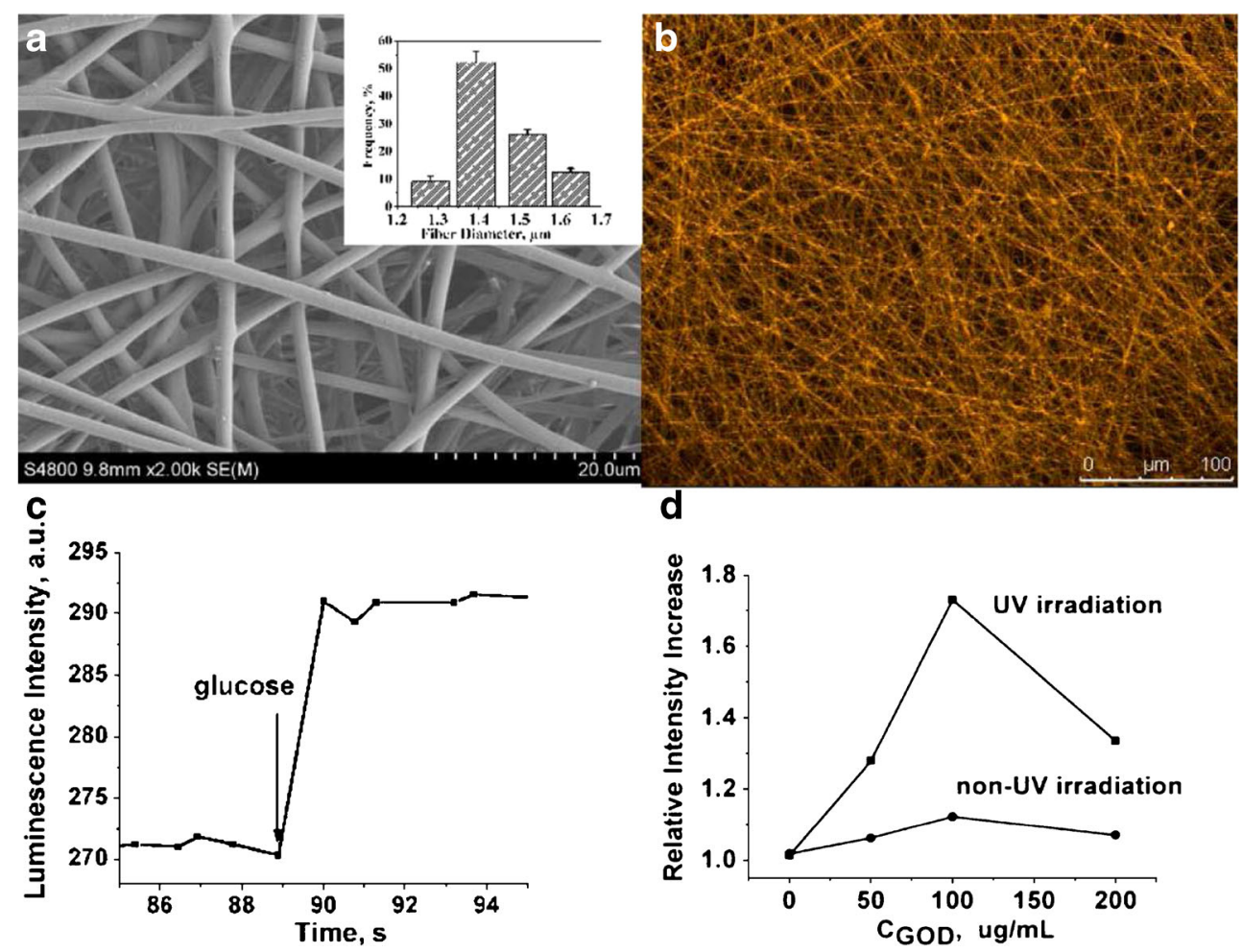

d

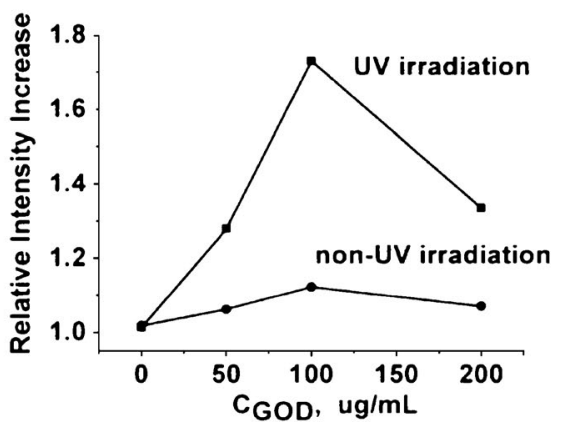


Fig. 15 In vivo comparison of glucose-sensitive nanoparticles and nanofiber scaffolds. Mice were injected with glucosesensitive nanoparticles and nanofiber scaffolds along their backs and then imaged with a fluorescent small animal imager for $1 \mathrm{~h}$ and then at $3 \mathrm{~h}$ postinjection. Shown here are the fluorescent images from one mouse over this time frame. [Reprinted with permission from [228] (C) 2015 Royal Society of Chemistry]

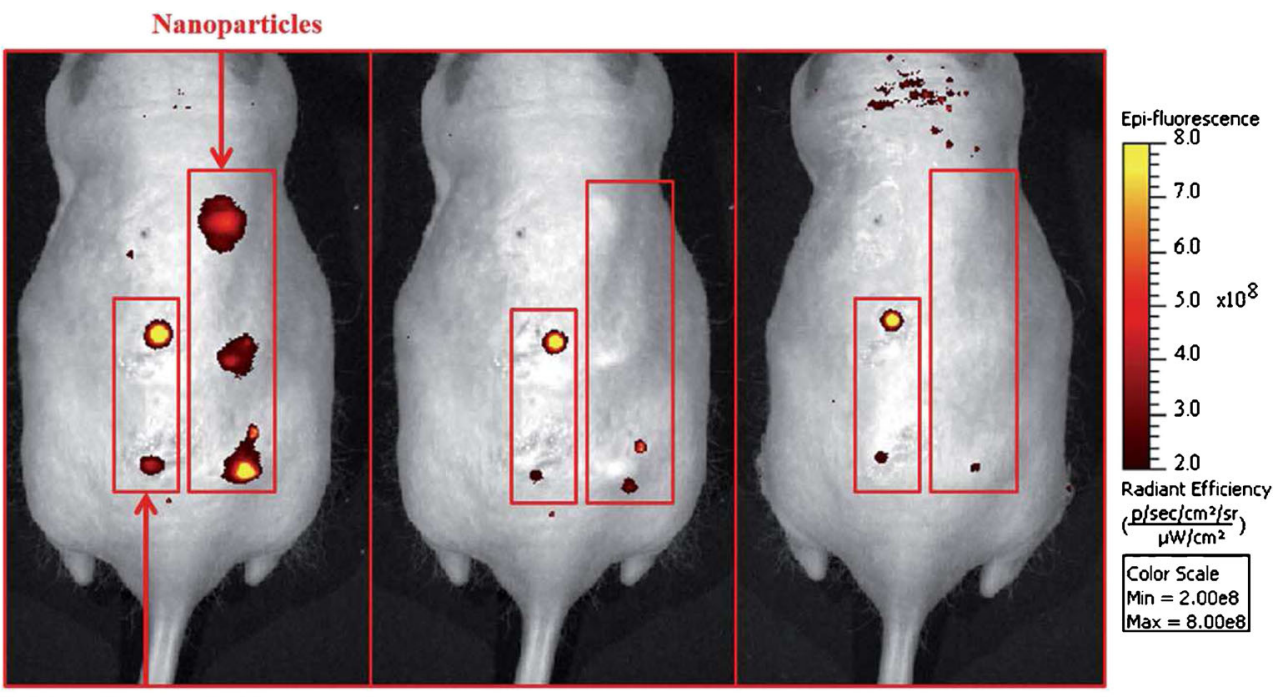

Nanofiber Scaffolds

Time 0 h
Time 1 h
Time 3 h
Also, recent studies by Balaconis, M. K. et al. showed the development of a stable glucose-sensitive nanofiber for in vivo monitoring of glucose [228]. A competitive binding interaction between boronic acids and diols on either alizarin or glucose is the reason for the sensors' response to glucose. The boronic acid binds to the diol on alizarin and statically quenches the fluorescence in the absence of glucose. If the concentration of glucose increases, these molecules displace the alizarin and result in fluorescence. The spherical or nanofiber nanosensors are implanted subdermally (Fig. 15) to demonstrate that the nanofiber nanosensors enhance resident time at the

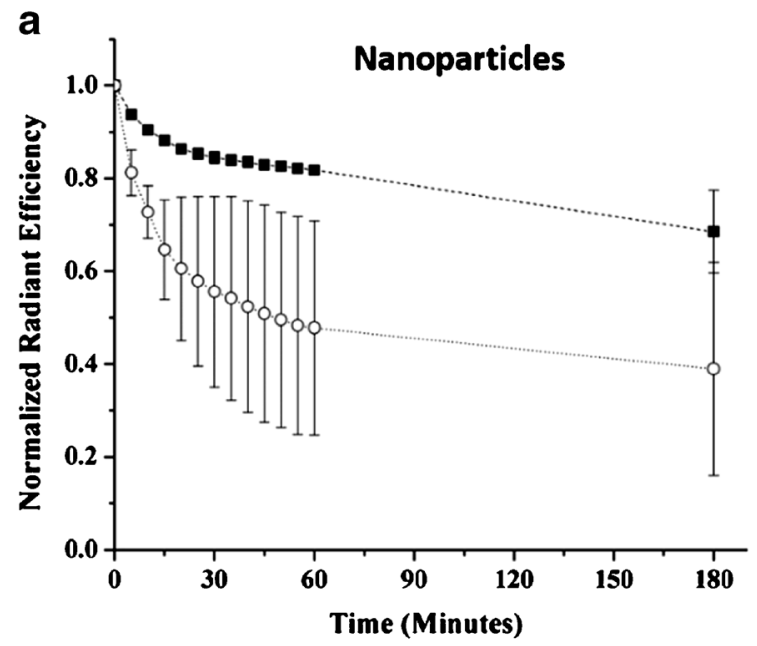

Fig. 16 Fluorescence measurements of glucose-sensitive nanoparticles and nanofiber scaffolds over time in vivo. (A) The average normalized total radiant efficiency of glucose-sensitive nanoparticle scaffolds both in vivo( $(\circ)$ and in vitro control (a) were plotted over time. (B) The average normalized total radiant efficiency of nanofiber scaffolds both in vivo(o) and in vitro control (a) were plotted over time. The implantation site and their loss in signal is directly compared with in vitro signal loss.

As a result, the loss of radiant efficiency at the injection site is significantly higher than the signal loss observed in vitro for spherical nanosensors. The reason for in vitro signal loss is attributable to leaching of boronic acid from the hydrophobic core, and the difference in signal loss between in vivo and in vitro is ascribed to nanosensor diffusion away from the implantation site. Conversely, a very closely matched signal loss between the in vivo and in vitro experiments was noticed after $1 \mathrm{~h}$, and they were further comparable after $3 \mathrm{~h}$, as illustrated in Fig. 16. b

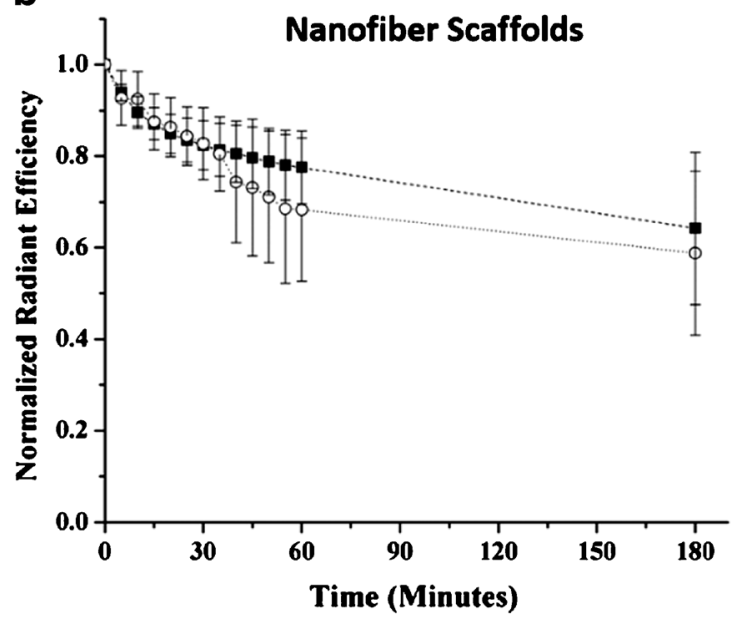

normalized in vivo average for nanoparticles and nanofiber scaffolds was calculated across three different mice with $n_{\text {nanoparticles }}=8$ and $n_{\text {nanofiber scaffolds }}=6$ injection spots. Similarly, the normalized in vitro average was calculated from $n_{\text {nanoparticles }}=8$ and $n_{\text {nanofiber scaffolds }}=7$. Error bars represent standard deviations. [Reprinted with permission from [228] (C) 2015 Royal Society of Chemistry] 


\section{Concluding remarks}

This review addresses all recent notable developments in the field of electrospun nanofiber-based glucose sensors using various mechanisms. An excellent opportunity for effective immobilization of enzymes on their surface, along with enhanced interaction with analytes, improved oxidation process, and prolonged stability has been provided with the introduction of electrospun nanofibers in glucose sensing. Our indepth analysis has implied greater performance by the electrospun nanofiber-based sensors than the existing nanomaterial-based sensors even though they are very active. Remarkable results have proven that the combination of electrospun nanofibers and incorporated functional nanomaterials provide an efficient platform for developing a potential glucose sensor. The splendid features of electrospun nanofibers, with a special emphasis on their versatility and simplicity, are considered to be advancement in glucose sensing research. Nevertheless, a major challenge in developing a sensor is its leaching effect of functional nanomaterials, biocompatibility, and toxicity. As there is limited evidence to support the toxic nature of electrospun nanofibers and their composites, the safety and risks involved are an area of concern for future use and further research. Therefore, much effort is required to further explore the integration of newer materials with nanofibers for the emergence of an ultrasensitive, biocompatible, stable, and reliable sensor device for real-world applications.

Acknowledgments S.A. and B.B. thank the Scientific and Technological Research Council of Turkey (TÜBITAK) (TÜBITAK-BIDEB 2216, Research Fellowship Programme for Foreign Citizens) for postdoctoral fellowship funding. T.U. acknowledges partial support of The Turkish Academy of Sciences - Outstanding Young Scientists Award Program (TUBA-GEBIP).

Conflict of interest The authors declare no conflicts of interest.

\section{References}

1. Lin Y, Yu P, Hao J, Wang Y, Ohsaka T, Mao L (2014) Continuous and simultaneous electrochemical measurements of glucose, lactate, and ascorbate in rat brain following brain ischemia. Anal Chem 86:3895-3901

2. Odaci D, Gacal BN, Gacal B, Timur S, Yagci Y (2009) Fluorescence sensing of glucose using glucose oxidase modified by PVA-pyrene prepared via "click" chemistry. Biomacromolecules 10:2928-2934

3. Kropff J, Bruttomesso D, Doll W, Farret A, Galasso S, Luijf YM, Mader JK, Place J, Boscari F, Pieber TR, Renard E, DeVries JH (2015) Accuracy of two continuous glucose monitoring systems: to-head comparison under clinical research centre and daily life. Diabetes Obes Metab 17:343-349
4. Benassi K, Drobny J, Aye T (2013) Real-time continuous glucose monitoring systems in the classroom/school environment. Diabetes Technol Ther 15:409-412

5. Diagnosing Diabetes and Learning About Prediabetes. American Diabetes Association. Available at: http://www.diabetes.org/ diabetes-basics/diagnosis/?loc $=$ db-slabnav. Accessed 12 September 2015

6. International Diabetic Federation (2013) Annual report. 1-37. Available at: http://www.idf.org/sites/default/files/attachments/ IDF-AR2013-final-rv.pdf. Accessed 12 September 2015

7. Clark LC Jr, Lyons C (1962) Electrode systems for continuous monitoring in cardiovascular surgery. Ann NY Acad Sci 102:29 45

8. Updike SJ, Hicks GP (1967) The enzyme electrode. Nature 214: 986-988

9. McNichols RJ, Coté GL (2000) Optical glucose sensing in biological fluids: an overview. J Biomed Opt 5:5-16

10. Endo T, Ikeda R, Yanagida Y, Hatsuzawa T (2008) Stimuliresponsive hydrogel-silver nanoparticles composite for development of localized surface plasmon resonance-based optical biosensor. Anal Chim Acta 611:205-211

11. Steiner M-S, Duerkop A, Wolfbeis OS (2011) Optical methods for sensing glucose. Chem Soc Rev 40:4805-4839

12. Barone PW, Strano MS (2009) Single walled carbon nanotubes as reporters for the optical detection of glucose. J Diabetes Sci Technol 3:242-252

13. Zhou YG, Yang S, Qian QY, Xia XH (2009) Gold nanoparticles integrated in a nanotube array for electrochemical detection of glucose. Electrochem Commun 11:216-219

14. Wang J, Thomas DF, Chen A (2008) Nonenzymatic electrochemical glucose sensor based on nanoporous PtPb networks. Anal Chem 80:997-1004

15. Su C, Zhang C, Lu G, Ma C (2010) Nonenzymatic electrochemical glucose sensor based on Pt nanoparticles/mesoporous carbon matrix. Electroanalysis 22:1901-1905

16. Li H, Liu S, Dai Z, Bao J, Yang X (2009) Applications of nanomaterials in electrochemical enzyme biosensors. Sensors 9: $8547-8561$

17. du Toit H, Di Lorenzo M (2014) Glucose oxidase directly immobilized onto highly porous gold electrodes for sensing and fuel cell applications. Electrochim Acta 138:86-92

18. Wang Y, Liu L, Li M, Xu S, Gao F (2011) Multifunctional carbon nanotubes for direct electrochemistry of glucose oxidase and glucose bioassay. Biosens Bioelectron 30:107111

19. Cui HF, Zhang K, Zhang YF, Sun YL, Wang J, Zhang WD, Luong JHT (2013) Immobilization of glucose oxidase into a nanoporous $\mathrm{TiO}_{2}$ film layered on metallophthalocyanine modified verticallyaligned carbon nanotubes for efficient direct electron transfer. Biosens Bioelectron 46:113-118

20. Si P, Huang Y, Wang T, Ma J (2013) Nanomaterials for electrochemical nonenzymatic glucose biosensors. RSC Adv 3:34873502

21. Pradhan D, Niroui F, Leung KT (2010) High-performance, flexible enzymatic glucose biosensor based on $\mathrm{ZnO}$ nanowires supported on a gold-coated polyester substrate. ACS Appl Mater Interfaces 2:2409-2412

22. Yang X, Bai J, Wang Y, Jiang X, He X (2012) Hydrogen peroxide and glucose biosensor based on silver nanowires synthesized by polyol process. Analyst 137:4362-4367

23. Cherevko S, Chung CH (2009) Gold nanowire array electrode for nonenzymatic voltammetric and amperometric glucose detection. Sensors Actuators B Chem 142:216-223

24. Tarlani A, Fallah M, Lotfi B, Khazraei A, Golsanamlou S, Muzart J, Mirza-Aghayan M (2015) New ZnO nanostructures as nonenzymatic glucose biosensors. Biosens Bioelectron 67:601-607 
25. Claussen JC, Kim SS, Haque AU, Artiles MS, Porterfield DM, Fisher TS (2010) Electrochemical glucose biosensor of platinum nanospheres connected by carbon nanotubes. J Diabetes Sci Technol 4:312-319

26. Alwarappan S, Liu C, Kumar A, Li CZ (2010) Enzyme-doped graphene nanosheets for enhanced glucose biosensing. J Phys Chem C 114:12920-12924

27. Ding Y, Wang Y, Su L, Bellagamba M, Zhang H, Lei Y (2010) Electrospun $\mathrm{Co}_{3} \mathrm{O}_{4}$ nanofibers for sensitive and selective glucose detection. Biosens Bioelectron 26:542-548

28. Li Z, Xin Y, Zhang Z, Wu H, Wang P (2015) Rational design of binder-free noble metal/metal oxide arrays with nanocauliflower structure for wide linear range nonenzymatic glucose detection. Sci Rep 5:10617

29. Huang S, Ding Y, Liu Y, Su L, Filosa R, Lei Y (2011) Glucose biosensor using glucose oxidase and electrospun $\mathrm{Mn}_{2} \mathrm{O}_{3}-\mathrm{Ag}$ nanofibers. Electroanalysis 23:1912-1920

30. Scampicchio M, Arecchi A, Lawrence NS, Mannino S (2010) Nylon nanofibrous membrane for mediated glucose biosensing. Sensors Actuators B Chem 145:394-397

31. Umar A, Rahman MM, Al-Hajry A, Hahn YB (2009) Enzymatic glucose biosensor based on flower-shaped copper oxide nanostructures composed of thin nanosheets. Electrochem Commun $11: 278-281$

32. Wang X, Hu C, Liu H, Du G, He X, Xi Y (2010) Synthesis of CuO nanostructures and their application for nonenzymatic glucose sensing. Sensors Actuators B Chem 144:220-225

33. Zhang Y, Wang Y, Jia J, Wang J (2012) Nonenzymatic glucose sensor based on graphene oxide and electrospun $\mathrm{NiO}$ nanofibers. Sensors Actuators B Chem 171(172):580-587

34. Zhang Y, Liu S, Li Y, Deng D, Si X, Ding Y, He H, Luo L, Wang Z (2015) Electrospun graphene decorated $\mathrm{MnCo}_{2} \mathrm{O}_{4}$ composite nanofibers for glucose biosensing. Biosens Bioelectron 66:308315

35. Wang ZG, Wang Y, Xu H, Li G, Xu ZK (2009) Carbon nanotubefilled nanofibrous membranes electrospun from poly(acrylonitrileco-acrylic acid) for glucose biosensor. J Phys Chem C 113:29552960

36. Manesh KM, Kim HT, Santhosh P, Gopalan AI, Lee KP (2008) A novel glucose biosensor based on immobilization of glucose oxidase into multiwall carbon nanotubes-polyelectrolyte-loaded electrospun nanofibrous membrane. Biosens Bioelectron 23: 771-779

37. Bai Y, Yang H, Yang W, Li Y, Sun C (2007) Gold nanoparticlesmesoporous silica composite used as an enzyme immobilization matrix for amperometric glucose biosensor construction. Sensors Actuators B Chem 124:179-186

38. Zhao L, Wu G, Cai Z, Zhao T, Yao Q, Chen X (2015) Ultrasensitive nonenzymatic glucose sensing at near-neutral $\mathrm{pH}$ values via anodic stripping voltammetry using a glassy carbon electrode modified with Pt3Pd nanoparticles and reduced graphene oxide. Microchim Acta 182:2055-2060

39. Solanki PR, Kaushik A, Agrawal VV, Malhotra BD (2011) Nanostructured metal oxide-based biosensors. NPG Asia Mater 3:17-24

40. Cash KJ, Clark HA (2010) Nanosensors and nanomaterials for monitoring glucose in diabetes. Trends Mol Med 16:584-593

41. Nitinaivinij K, Parnklang T, Thammacharoen C, Ekgasita S, Wongravee K (2014) Colorimetric determination of hydrogen peroxide by morphological decomposition of silver nanoprisms coupled with chromaticity analysis. Anal Methods 6:9816-9824

42. Rahman MM, Ahammad AJS, Jin JH, Ahn SJ, Lee JJ (2010) A comprehensive review of glucose biosensors based on nanostructured metal-oxides. Sensors 10:4855-4886

43. Senthamizhan A, Celebioglu A, Uyar T (2015) Ultrafast on-site selective visual detection of TNT at sub-ppt level using fluorescent gold cluster incorporated single nanofiber. Chem Commun 51: 5590-5593

44. Senthamizhan A, Celebioglu A, Uyar T (2014) Flexible and highly stable electrospun nanofibrous membrane incorporating gold nanoclusters as an efficient probe for visual colorimetric detection of $\mathrm{Hg}(\mathrm{II})$. J Mater Chem A 2:12717-12723

45. Nakabayashi Y, Hirosaki Y, Yamauchi O (2006) Dipolar ruthenium-ammine complexes with 4,4'-bipyridinium ions accessible for both amperometric and colorimetric glucose sensors. Inorg Chem Commun 9:935-938

46. Zhou B, Wang J, Guo Z, Tan H, Zhu X (2006) A simple colorimetric method for determination of hydrogen peroxide in plant tissues. Plant Growth Regul 49:113-118

47. Chigome S, Torto N (2011) A review of opportunities for electrospun nanofibers in analytical chemistry. Anal Chim Acta 706:25-36

48. Ondigo DA, Tshentu ZR, Torto N (2013) Electrospun nanofibebased colorimetric probe for rapid detection of $\mathrm{Fe}^{2+}$ in water. Anal Chim Acta 804:228-234

49. Mudabuka B, Ondigo D, Degni S, Vilakazi S, Torto N (2014) A colorimetric probe for ascorbic acid based on copper-gold nanoparticles in electrospun nylon. Microchim Acta 181:395-401

50. Wang X, Si Y, Wang J, Ding B, Yu J, Al-Deyab SS (2012) A facile and highly sensitive colorimetric sensor for the detection of formaldehyde based on electro-spinning/netting nano-fiber/nets. Sensors Actuators B Chem 163:186-193

51. Gao F, Luo F, Chen X, Yao W, Yin J, Yao Z, Wang L (2009) A novel nonenzymatic fluorescent sensor for glucose based on silica nanoparticles doped with europium coordination compound. Talanta 80:202-206

52. Kochubey VI, Volkova EK, Konyukhova JG (2014) Fluorescent $\mathrm{ZnCdS}$ nanoparticles for glucose sensing. J Biomed Opt 19: 011020

53. Li J, Li Y, Shahzad SA, Chen J, Chen Y, Wang Y, Yang M, Yu C (2015) Fluorescence turn-on detection of glucose via the Ag nanoparticle mediated release of a perylene probe. Chem Commun 51: 6354-6356

54. Ding B, Yu J (2014) Electrospun nanofibers for energy and environmental applications. Springer, Berlin, Germany

55. Senthamizhan A, Celebioglu A, Bayir S, Gorur M, Doganci E, Yilmaz F, Uyar T (2015) Highly fluorescent pyrene-functional polystyrene copolymer nanofibers for enhanced sensing performance of TNT. ACS Appl Mater Interfaces. doi:10.1021/acsami. 5 b07184

56. Thavasi V, Singh G, Ramakrishna S (2008) Electrospun nanofibers in energy and environmental applications. Energy Environ Sci 1:205-221

57. Fang J, Niu H, Lin T, Wang X (2008) Applications of electrospun nanofibers. Chin Sci Bull 53:2265-2286

58. Celebioglu A, Umu OC, Tekinay T, Uyar T (2013) Antibacterial electrospun nanofibers from triclosan/cyclodextrin inclusion complexes. Colloids Surf B: Biointerfaces 116:612-619

59. Uyar T, Havelund R, Nur Y, Balan A, Hacaloglu J, Toppare L, Besenbacher F, Kingshott P (2010) Cyclodextrin functionalized poly(methyl methacrylate) (PMMA) electrospun nanofibers for organic vapors waste treatment. J Membr Sci 365:409-417

60. Anitha S, Brabu B, Rajesh KP, Natarajan TS (2013) Fabrication of UV sensor based on electrospun composite fibers. Mater Lett 92: $417-420$

61. Anitha S, Brabu B, Thiruvadigal DJ, Gopalakrishnan C, Natarajan TS (2013) Optical, bactericidal, and water repellent properties of electrospun nano-composite membranes of cellulose acetate and ZnO. Carbohydr Polym 97:856-863

62. Anitha S, Brabu B, Thiruvadigal DJ, Gopalakrishnan C, Natarajan TS (2012) Preparation of free-standing electrospun composite 
$\mathrm{ZnO}$ membranefor antibacterial applications. Adv Sci Lett 5:468477

63. Senthamizhan A, Uyar T (2015) In: Macagnano A, Zampetti E, Kny E (eds) Electrospinning for high performance sensors, 1st edn. Springer International Publishing, Switzerland

64. Hu X, Liu S, Zhou G, Huang Y, Xie Z, Jing X (2014) Electrospinning of polymeric nanofibers for drug delivery applications. J Control Release 185:12-21

65. Dong Z, Kennedy SJ, Wu Y (2011) Electrospinning materials for energy-related applications and devices. J Power Sources 196: 4886-4904

66. Senthamizhan A, Celebioglu A, Balusamy B, Uyar T (2015) Immobilization of gold nanoclusters inside porous electrospun fibers for selective detection of $\mathrm{Cu}$ (II): a strategic approach to shielding pristine performance. Sci Rep 5:15608

67. Wang ZG, Wan LS, Liu ZM, Huang XJ, Xu ZK (2009) Enzyme immobilization on electrospun polymer nanofibers: an overview. $\mathrm{J}$ Mol Catal B Enzym 56:189-195

68. Wang J (2008) Electrochemical glucose biosensors. Chem Rev 108:814-825

69. Heller A, Feldman B (2008) Electrochemical glucose sensors and their applications in diabetes management. Chem Rev 108:24822505

70. Song C, Pehrsson PE, Zhao W (2006) Optical enzymatic detection of glucose based on hydrogen peroxide-sensitive HiPco carbon nanotubes. J Mater Res 21:2817-2823

71. Cheng Z, Wang E, Yang X (2001) Capacitive detection of glucose using molecularly imprinted polymers. Biosens Bioelectron 16: 179-185

72. Nakamura H, Mogi Y, Akimoto T, Naemura K, Kato T, Yano K, Karube I (2008) An enzyme-chromogenic surface plasmon resonance biosensor probe for hydrogen peroxide determination using a modified Trinder's reagent. Biosens Bioelectron 24:455-460

73. Sophia J, Muralidharan G (2015) Gold nanoparticles for sensitive detection of hydrogen peroxide: a simple nonenzymatic approach. J Appl Electrochem 45:963-971

74. Tura A, Sbrignadello S, Cianciavicchia D, Pacini G, Ravazzani P (2010) A low frequency electromagnetic sensor for indirect measurement of glucose concentration: in vitro experiments in different conductive solutions. Sensors 10:5346-5358

75. Gourzi M, Rouane A, Guelaz R, Alavi MS, McHugh MB, Nadi M, Roth P (2005) Noninvasive glycaemia blood measurements by electromagnetic sensor: study in static and dynamic blood circulation. J Med Eng Technol 29:22-26

76. Wilson R, Turner APF (1992) Glucose oxidase: an ideal enzyme. Biosens Bioelectron 7:165-185

77. Al-Halhouli A, Demming S, Alahmad L, LIobera A, Büttgenbach $\mathrm{S}$ (2014) An in-line photonic biosensor for monitoring of glucose concentrations. Sensors 14:15749-15759

78. Park S, Boo H, Chung TD (2006) Electrochemical nonenzymatic glucose sensors. Anal Chim Acta 556:46-57

79. Clark L Jr (1970) US Patent 33,539,455

80. Chen C, Xie Q, Yang D, Xiao H, Fu Y, Tan Y, Yao S (2013) Recent advances in electrochemical glucose biosensors: a review. RSC Adv 3:4473-4491

81. Saleh FS, Mao L, Ohsaka T (2012) A promising dehydrogenasebased bioanode for a glucose biosensor and glucose $/ \mathrm{O}_{2}$ biofuel cell. Analyst 137:2233-2238

82. Yehezkeli O, Tel-Vered R, Raichlin S, Willner I (2011) Nanoengineered flavin-dependent glucose dehydrogenase/gold nanoparticle-modified electrodes for glucose sensing and biofuel cell applications. ACS Nano 5:2385-2391

83. Zayats M, Katz E, Baron R, Willner I (2005) Reconstitution of apo-glucose dehydrogenase on pyrroloquinoline quinonefunctionalized $\mathrm{Au}$ nanoparticles yields an electrically contacted biocatalyst. J Am Chem Soc 127:12400-12406
84. Zafar MN, Wang X, Sygmund C, Ludwig R, Leech D, Gorton L (2012) Electron-transfer studies with a new flavin adenine dinucleotide-dependent glucose dehydrogenase and osmium polymers of different redox potentials. Anal Chem 84:334-341

85. Lewis BE, Schramm VL (2003) Binding equilibrium isotope effects for glucose at the catalytic domain of human brain hexokinase. J Am Chem Soc 125:4785-4798

86. Anicet N, Bourdillon C, Moiroux J, Savéant JM (1999) Step-bystep avidin-biotin construction of bienzyme electrodes. Kinetic analysis of the coupling between the catalytic activities of immobilized monomolecular layers of glucose oxidase and hexokinase. Langmuir 15:6527-6533

87. Bunte C, Prucker O, König T, Rühe J (2010) Enzyme containing redox polymer networks for biosensors or biofuel cells: a photochemical approach. Langmuir 26:6019-6027

88. Toghill KE, Compton RG (2010) Electrochemical nonenzymatic glucose sensors: a perspective and an evaluation. Int $\mathrm{J}$ Electrochem Sci 5:1246-1301

89. Cass AEG, Davis G, Francis GD, Hill HAO, Aston WJ, Higgins IJ, Plotkin EV, Scott LDL, Turner APF (1984) Ferrocenemediated enzyme electrode for amperometric determination of glucose. Anal Chem 56:667-671

90. Tsujimura S, Kojima S, Kano K, Ikeda T, Sato M, Sanada H, Omura H (2006) Novel FAD-dependent glucose dehydrogenase for a dioxygen-insensitive glucose biosensor. Biosci Biotechnol Biochem 70:654-659

91. Lau KT, De Fortescu SAL, Murphy LJ, Slater JM (2003) Disposable glucose sensors for flow injection analysis using substituted 1,4-benzoquinone mediators. Electroanalysis 15: 975-981

92. Taylor C, Kenausis G, Katakis I, Heller A (1995) "Wiring" of glucose oxidase within a hydrogel made with polyvinyl imidazole complexed with $\left[\left(\mathrm{Os}-4,4^{\prime} \text {-dimethoxy-2,2'-bipyridine }\right) \mathrm{Cl}\right]^{+} p^{2+1}$. J Electroanal Chem 396:511-515

93. Katakis I, Dominguez E (1995) Characterization and stabilization of enzyme biosensors. Trends Anal Chem 14:310-319

94. Schugerl K, Hitzmann B, Jurgens H, Kullick T, Ulber R, Weigal B (1996) Challenges in integrating biosensors and FIA for on-line monitoring and control. Trends Biotechnol 14:21-31

95. Li J, Lin X (2007) Glucose biosensor based on immobilization of glucose oxidase in poly(o-aminophenol) film on polypyrrole-Pt nanocomposite modified glassy carbon electrode. Biosens Bioelectron 22:2898-2905

96. Loeb W (1909) Biochem Z 17:132

97. Luo D, Wu L, Zhi J (2009) Fabrication of boron-doped diamond nanorod forest electrodes and their application in nonenzymatic amperometric glucose biosensing. ACS Nano 3:2121-2128

98. Gao H, Xiao F, Ching CB, Duan H (2011) One-step electrochemical synthesis of PtNi nanoparticle-graphene nanocomposites for nonenzymatic amperometric glucose detection. ACS Appl Mater Interfaces 3:3049-3057

99. Tian K, Prestgard M, Tiwari A (2014) A review of recent advances in nonenzymatic glucose sensors. Mater Sci Eng C 41:100-118

100. Kang X, Mai Z, Zou X, Cai P, Mo J (2008) Glucose biosensors based on platinum nanoparticles-deposited carbon nanotubes in sol-gel chitosan/silica hybrid. Talanta 74:879-886

101. Feng D, Wang F, Chen Z (2009) Electrochemical glucose sensor based on one-step construction of gold nanoparticle-chitosan composite film. Sensors Actuators B Chem 138:539-544

102. Bai H, Han M, Du Y, Bao J, Dai Z (2010) Facile synthesis of porous tubular palladium nanostructures and their application in a nonenzymatic glucose sensor. Chem Commun 46:1739-1741

103. Lu LM, Zhang L, Qu FL, Lu HX, Zhang XB, Wu ZS, Huan SY, Wang QA, Shen GL, Yu RQ (2009) A nano-Ni based ultrasensitive nonenzymatic electrochemical sensor for glucose: enhancing 
sensitivity through a nanowire array strategy. Biosens Bioelectron 25:218-223

104. Huang TK, Lin KW, Tung SP, Cheng TM, Chang IC, Hsieh YZ, Lee CY, Chiu HT (2009) Glucose sensing by electrochemically grown copper nanobelt electrode. J Electroanal Chem 636:123127

105. Reitz E, Jia W, Gentile M, Wang Y, Lei Y (2008) CuO nanospheres based nonenzymatic glucose sensor. Electroanalysis 20: 2482-2486

106. Dong XC, Xu H, Wang XW, Huang YX, Chan-Park MB, Zhang H, Wang LH, Huang W, Chen P (2012) 3D graphene-cobalt oxide electrode for high-performance supercapacitor and enzymeless glucose detection. ACS Nano 6:3206-3213

107. Li C, Liu Y, Li L, Du Z, Xu S, Zhang M, Yin X, Wang T (2008) A novel amperometric biosensor based on $\mathrm{NiO}$ hollow nanospheres for biosensing glucose. Talanta 77:455-459

108. Umar A, Rahman MM, Hahn YB (2009) MgO polyhedral nanocages and nanocrystals based glucose biosensor. Electrochem Commun 11:1353-1357

109. Kong T, Chen Y, Ye Y, Zhang K, Wang Z, Wang X (2009) An amperometric glucose biosensor based on the immobilization of glucose oxidase on the $\mathrm{ZnO}$ nanotubes. Sensors Actuators B Chem 138:344-350

110. Cao X, Wang N (2011) A novel nonenzymatic glucose sensor modified with $\mathrm{Fe}_{2} \mathrm{O}_{3}$ nanowire arrays. Analyst 136:4241-4246

111. Wang X, Zhang Y, Banks CE, Chen Q, Ji X (2010) Nonenzymatic amperometric glucose biosensor based on nickel hexacyanoferrate nanoparticle film modified electrodes. Colloids Surfaces B Biointerfaces 78:363-366

112. Bai Y, Sun Y, Sun C (2008) Pt-Pb nanowire array electrode for enzyme-free glucose detection. Biosens Bioelectron 24:579-585

113. Li LH, Zhang WD, Ye JS (2008) Electrocatalytic oxidation of glucose at carbon nanotubes supported PtRu nanoparticles and its detection. Electroanalysis 20:2212-2216

114. Holt-Hindle P, Nigro S, Asmussen M, Chen A (2008) Amperometric glucose sensor based on platinum-iridium nanomaterials. Electrochem Commun 10:1438-1441

115. Mahshid SS, Mahshid S, Dolati A, Ghorbani M, Yang L, Luo S, Cai Q (2011) Template-based electrodeposition of $\mathrm{Pt} / \mathrm{Ni}$ nanowires and its catalytic activity towards glucose oxidation. Electrochim Acta 58:551-555

116. Ryu J, Kim K, Kim HS, Hahn HT, Lashmore D (2010) Intense pulsed light induced platinum-gold alloy formation on carbon nanotubes for nonenzymatic glucose detection. Biosens Bioelectron 26:602-607

117. Tominaga M, Shimazoe T, Nagashima M, Taniguchi I (2008) Composition-activity relationships of carbon electrodesupported bimetallic gold-silver nanoparticles in electrocatalytic oxidation of glucose. J Electroanal Chem 615:51-61

118. Yi Q, Yu W, Niu F (2010) Novel nanoporous binary Au-Ru electrocatalysts for glucose oxidation. Electroanalysis 22:556-563

119. Chen LY, Fujita T, Ding Y, Chen MW (2010) A three-dimensional gold-decorated nanoporous copper core-shell composite for electrocatalysis and nonenzymatic biosensing. Adv Funct Mater 20:2279-2285

120. Ni Y, Jin L, Zhanga L, Hong J (2010) Honeycomb-like Ni@C composite nanostructures: synthesis, properties and applications in the detection of glucose and the removal of heavy-metal ions. J Mater Chem 20:6430-6436

121. Ding Y, Liu Y, Zhang L, Wang Y, Bellagamba M, Parisi J, Li CM, Lei Y (2011) Sensitive and selective nonenzymatic glucose detection using functional NiO-Pt hybrid nanofibers. Electrochim Acta 58:209-214

122. Zhang X, Gu A, Wang G, Huang Y, Ji H, Fang B (2011) Porous $\mathrm{Cu}-\mathrm{NiO}$ modified glass carbon electrode enhanced nonenzymatic glucose electrochemical sensors. Analyst 136:5175-5180
123. Kumar SA, Cheng HW, Chen SM, Wang SF (2010) Preparation and characterization of copper nanoparticles/zinc oxide composite modified electrode and its application to glucose sensing. Mater Sci Eng C 30:86-91

124. Wang AJ, Feng JJ, Li ZH, Liao QC, Wang ZZ, Chen JR (2012) Solvothermal synthesis of $\mathrm{Cu} / \mathrm{Cu}_{2} \mathrm{O}$ hollow microspheres for nonenzymatic amperometric glucose sensing. Cryst Eng Comm 14: 1289

125. Wang W, Li Z, Zheng W, Yang J, Zhang H, Wang C (2009) Electrospun palladium (IV)-doped copper oxide composite nanofibers for nonenzymatic glucose sensors. Electrochem Commun 11:1811-1814

126. Luo S, Su F, Liu C, Li J, Liu R, Xiao Y, Li Y, Liu X, Cai Q (2011) A new method for fabricating a $\mathrm{CuO} / \mathrm{TiO}_{2}$ nanotube arrays electrode and its application as a sensitive nonenzymatic glucose sensor. Talanta 86:157-163

127. Ding Y, Wang Y, Zhang L, Zhang H, Lei Y (2012) Preparation, characterization and application of novel conductive $\mathrm{NiO}-\mathrm{CdO}$ nanofibers with dislocation feature. J Mater Chem 22:980-986

128. Cao L, Ye J, Tong L, Tang B (2008) A new route to the considerable enhancement of glucose oxidase (GOx) activity: the simple assembly of a complex from CdTe quantum dots and GOx, and its glucose sensing. Chem Eur J 14:9633-9640

129. Wu P, He Y, Wang HF, Yan XP (2010) Conjugation of glucose oxidase onto Mn-doped Zns quantum dots for phosphorescent sensing of glucose in biological fluids. Anal Chem 82:1427-1433

130. Sun J, Zhu Y, Yang X, Li C (2009) Photoelectrochemical glucose biosensor incorporating CdS nanoparticles. Particuology 7:347352

131. Wang Z, Liu S, Wu P, Cai C (2009) Detection of glucose based on direct electron transfer reaction of glucose oxidase immobilized on highly ordered polyaniline nanotubes. Anal Chem 81:1638-1645

132. Zenkl G, Mayr T, Klimant I (2008) Sugar-responsive fluorescent nanospheres. Macromol Biosci 8:146-152

133. Lin LH, Shih JS (2011) Immobilized fullerene C60-enzyme-based electrochemical glucose sensor. J Chin Chem Soc 58:228-235

134. Zhu Z, Garcia-Gancedo L, Flewitt AJ, Xie H, Moussy F, Milne WI (2012) A critical review of glucose biosensors based on carbon nanomaterials: carbon nanotubes and graphene. Sensors 12:59966022

135. Rathod D, Dickinson C, Egan D, Dempsey E (2010) Platinum nanoparticle decoration of carbon materials with applications in nonenzymatic glucose sensing. Sensors Actuators B Chem 143: $547-554$

136. Agarwal S, Greiner A, Wendorff JH (2009) Electrospinning of manmade and biopolymer nanofibers - progress in techniques, materials, and applications. Adv Funct Mater 19:2863-2879

137. Lu X, Wang C, Wei Y (2009) One-dimensional composite nanomaterials: synthesis by electrospinning and their applications. Small 5:2349-2370

138. Ramaseshan R, Sundarrajan S, Jose R, Ramakrishna S (2007) Nanostructured ceramics by electrospinning. J Appl Phys 102: 111101

139. Wu H, Pan W, Lin D, Li H (2012) Electrospinning of ceramic nanofibers: fabrication assembly and applications. J Adv Ceram $1: 2-23$

140. Celebioglu A, Uyar T (2012) Electrospinning of nanofibers from non-polymeric systems: polymer-free nanofibers from cyclodextrin derivatives. Nanoscale 4:621-631

141. Fong H, Chun I, Reneker DH (1999) Beaded nanofibers formed during electrospinning. Polymer 40:4585-4592

142. Casper CL, Stephens JS, Tassi NG, Chase DB, Rabolt JF (2004) Controlling surface morphology of electrospun polystyrene fibers: effect of humidity and molecular weight in the electrospinning process. Macromolecules 37:573-578 
143. Thompson CJ, Chase GG, Yarin AL, Reneker DH (2007) Effects of parameters on nanofiber diameter determined from electrospinning model. Polymer 48:6913-6922

144. Ramakrishna S, Fujihara K, Teo WE, Lim TC, Ma Z (2005) An introduction to electrospinning and nanofibers. World Scientific Publishing Co. Pte. Ltd, Singapore

145. Wendorff JH, Agarwal S, Greiner A (2012) Electrospinning: materials, processing, and applications. Wiley-VCH Verlag GmbH \& Co. KGaA, Weinheim, Germany

146. Greiner A, Wendorff JH (2007) Electrospinning: a fascinating method for the preparation of ultrathin fibers. Angew Chem Int Ed 46:5670-5703

147. Uyar T, Besenbacher F (2008) Electrospinning of uniform polystyrene fibers: the effect of solvent conductivity. Polymer 49: 5336-5343

148. Celebioglu A, Uyar T (2011) Electrospun porous cellulose acetate fibers from volatile solvent mixture. Mater Lett 65:2291-2294

149. Persano L, Camposeo A, Tekmen C, Pisignano D (2013) Industrial upscaling of electrospinning and applications of polymer nanofibers: a review. Macromol Mater Eng 298:504-520

150. Yan G, Yu J, Qiu Y, Yi X, Lu J, Zhou X, Bai X (2011) Selfassembly of electrospun polymer nanofibers: a general phenomenon generating honeycomb-patterned nanofibrous structures. Langmuir 27:4285-4289

151. Sun B, Long YZ, Zhang HD, Li MM, Duvail JL, Jiang XY, Yin HL (2014) Advances in three-dimensional nanofibrous macrostructures via electrospinning. Prog Polym Sci 39:862-890

152. Dong H, Wang D, Sun G, Hinestroza JP (2008) Assembly of metal nanoparticles on electrospun nylon 6 nanofibers by control of interfacial hydrogen-bonding interactions. Chem Mater 20: $6627-6632$

153. Sahay R, Kumar PS, Sridhar R, Sundaramurthy J, Venugopal J, Mhaisalkar SG, Ramakrishna S (2012) Electrospun composite nanofibers and their multifaceted applications. J Mater Chem 22: 12953-12971

154. Tamaki T, Sugiyama T, Mizoe M, Oshiba Y, Yamaguchi T (2014) Reducing physical adsorption of enzymes by surface modification of carbon black for high-current-density biofuel cells. J Electrochem Soc 161:H3095-H3099

155. de Luiz MI, Lukachova LV, Gorton L, Laurell T, Karyakin AA (2001) Evaluation of glucose biosensors based on Prussian blue and lyophilised, crystalline, and cross-linked glucose oxidases (CLEC $\left.{ }^{\circledR}\right)$. Talanta 54:963-974

156. Hodak J, Etchenique R, Calvo EJ, Singhal K, Bartlett PN (1997) Layer-by-layer self-assembly of glucose oxidase with a poly(allylamine)ferrocene redox mediator. Langmuir 13:27082716

157. Guo C, Zhang X, Huo H, Xu C, Han X (2013) $\mathrm{Co}_{3} \mathrm{O}_{4}$ microspheres with free-standing nanofibers for high performance nonenzymatic glucose sensor. Analyst 138:6727-6731

158. Ramakrishna S, Mayer J, Wintermantel E, Leong KW (2001) Biomedical applications of polymer-composite materials: a review. Compos Sci Technol 61:1189-1224

159. Balazs AC, Emrick T, Russell TP (2006) Nanoparticle polymer composites: where two small worlds meet. Science 314:11071110

160. Sun HZ, Yang B (2008) In situ preparation of nanoparticles/ polymer composites. Sci Chin Ser E-Technol Sci 51:1886-1901

161. Schmidt G, Malwitz MM (2003) Properties of polymer-nanoparticle composites. Curr Opin Colloid Interface Sci 8:103-108

162. Vauthier C, Cabane B, Labarre D (2008) How to concentrate nanoparticles and avoid aggregation? Eur J Pharm Biopharm 69: 466-475

163. Mathew M, Sandhyarani N (2014) Detection of glucose using immobilized bienzyme on cyclic bisureas-gold nanoparticle conjugate. Anal Biochem 459:31-38
164. Jin C, Taniguchi I (2007) Electrocatalytic oxidation of glucose on gold nanocomposite electrodes. Chem Eng Technol 30:1298-1301

165. Li C, Su Y, Lv X, Xia H, Shi H, Yang X, Zhang J, Wang Y (2012) Controllable anchoring of gold nanoparticles to polypyrrole nanofibers by hydrogen bonding and their application in nonenzymatic glucose sensors. Biosens Bioelectron 38:402-406

166. Raicopol M, Prună A, Damian C, Pilan L (2013) Functionalized single-walled carbon nanotubes/polypyrrole composites for amperometric glucose biosensors. Nanoscale Res Lett 8:316

167. Forzani ES, Zhang H, Nagahara LA, Amlani I, Tsui R, Tao N (2004) A conducting polymer nanojunction sensor for glucose detection. Nano Lett 4:1785-1788

168. Nien PC, Tung TS, Ho KC (2006) Amperometric glucose biosensor based on entrapment of glucose oxidase in a poly $(3,4-$ ethylenedioxythiophene) film. Electroanalysis 18:1408-1415

169. Yang G, Kampstra KL, Abidian MR (2014) High-performance conducting polymer nanofiber biosensors for detection of biomolecules. Adv Mater 26:4954-4960

170. Macaya DJ, Nikolou M, Takamatsu S, Mabeck JT, Owens RM, Malliaras GG (2007) Simple glucose sensors with micromolar sensitivity based on organic electrochemical transistors. Sensors Actuators B Chem 123:374-378

171. Zhang M, Liao C, Mak CH, You P, Mak CL, Yan F (2015) Highly sensitive glucose sensors based on enzyme-modified wholegraphene solution-gated transistors. Sci Rep 5:8311

172. Olenic L, Mihailescu G, Pruneanu S, Lupu D, Biris AR, Margineanu P, Garabagiu S, Biris AS (2009) Investigation of carbon nanofibers as support for bioactive substances. J Mater Sci Mater Med 20:177-183

173. Periasamy AP, Chang YJ, Chen SM (2011) Amperometric glucose sensor based on glucose oxidase immobilized on gelatinmultiwalled carbon nanotube modified glassy carbon electrode. Bioelectrochemistry 80:114-120

174. Wu S, Ju HX, Liu Y (2007) Conductive mesocellular silica-carbon nanocomposite foams for immobilization, direct electrochemistry, and biosensing of proteins. Adv Funct Mater 17:585-592

175. Liu Y, Teng H, Hou H, You T (2009) Nonenzymatic glucose sensor based on renewable electrospun Ni nanoparticle-loaded carbon nanofiber paste electrode. Biosens Bioelectron 24:3329 3334

176. Zhang L, Li Y, Zhang Q, Wang H (2013) Hierarchical nanostructure of $\mathrm{WO}_{3}$ nanorods on $\mathrm{TiO}_{2}$ nanofibers and the enhanced visible light photocatalytic activity for degradation of organic pollutants. Cryst Eng Comm 15:5986-5993

177. Ostermann R, Li D, Yin Y, McCann JT, Xia Y (2006) $\mathrm{V}_{2} \mathrm{O}_{5}$ nanorods on $\mathrm{TiO}_{2}$ nanofibers: a new class of hierarchical nanostructures enabled by electrospinning and calcination. 6:1297-1302

178. Li M, Liu L, Xiong Y, Liu X, Nsabimana A, Bo X, Guo L (2015) Bimetallic $\mathrm{MCo}(\mathrm{M}=\mathrm{Cu}, \mathrm{Fe}, \mathrm{Ni}$, and $\mathrm{Mn})$ nanoparticles dopedcarbon nanofibers synthetized by electrospinning for nonenzymatic glucose detection. Sensors Actuators B Chem 207:614-622

179. Uzun SD, Kayaci F, Uyar T, Timur S, Toppare L (2014) Bioactive surface design based on functional composite electrospun nano fibers for biomolecule immobilization and biosensor applications. ACS Appl Mater Interfaces 6:5235-5243

180. Zhao M, Gao Y, Sun J, Gao F (2015) Mediatorless glucose biosensor and direct electron transfer type glucose/air biofuel cell enabled with carbon nanodots. Anal Chem 87:2615-2622

181. Cai C, Chen J (2004) Direct electron transfer of glucose oxidase promoted by carbon nanotubes. Anal Biochem 332: $75-83$

182. Zhang X, Liu D, Li L, You T (2015) Direct electrochemistry of glucose oxidase on novel free-standing nitrogen-doped carbon nanospheres@carbon nanofibers composite film. Sci Rep 5:9885 
183. Anitha S, Natarajan TS (2013) Fabrication of hierarchical ZnO enriched fibrous PVA membrane. J Nanosci Nanotechnol 13: 4256-4264

184. Anitha S, Thiruvadigal DJ, Natarajan TS (2011) In-situ preparation of high optical quality $\mathrm{ZnO}$ nanoparticles in nanofibrous PVA matrix. Mater Lett 65:2872-2876

185. Yuan Y, Zhao Y, Li H, Li Y, Gao X, Zheng C, Zhang J (2012) Electrospun metal oxide- $\mathrm{TiO}_{2}$ nanofibers for elemental mercury removal from flue gas. J Hazard Mater 227-228:427-435

186. Horzum N, Muñoz-Espí R, Glasser G, Demir MM, Landfester K, Crespy D (2012) Hierarchically structured metal oxide/silica nanofibers by colloid electrospinning. ACS Appl Mater Interfaces 4:6338-6345

187. Hwang SH, Song J, Jung Y, Kweon OY, Song H, Jang J (2011) Electrospun $\mathrm{ZnO} / \mathrm{TiO}_{2}$ composite nanofibers as a bactericidal agent. Chem Commun 47:9164-9166

188. Wang W, Li Z, Zheng W, Dong B, Li S, Wang C (2010) A novel nonenzymatic glucose sensor based on nickel (II) oxide electrospun nanofibers. J Nanosci Nanotechnol 10:7537-7540

189. Zheng B, Liu G, Yao A, Xiao Y, Du J, Guo Y, Xiao D, Hu Q, Choi MMF (2014) A sensitive AgNPs/CuO nanofibers nonenzymatic glucose sensor based on electrospinning technology. Sensors Actuators B Chem 195:431-438

190. Ahmad M, Pan C, Luo Z, Zhu J (2010) A single ZnO nanofiberbased highly sensitive amperometric glucose biosensor. J Phys Chem C 114:9308-9313

191. Lu N, Shao C, Li X, Shen T, Zhang M, Miao F, Zhang P, Zhang X, Wang $\mathrm{K}$, Zhang Y, Liu Y (2014) $\mathrm{CuO} / \mathrm{Cu}_{2} \mathrm{O}$ nanofibers as electrode materials for nonenzymatic glucose sensors with improved sensitivity. RSC Adv 4:31056-31061

192. Kayaci F, Ozgit-Akgun C, Biyikli N, Uyar T (2013) Surfacedecorated $\mathrm{ZnO}$ nanoparticles and $\mathrm{ZnO}$ nanocoating on electrospun polymeric nanofibers by atomic layer deposition for flexible photocatalytic nanofibrous membranes. RSC Adv 3:6817-6820

193. Deniz AE, Celebioglu A, Kayaci F, Uyar T (2011) Electrospun polymeric nanofibrous composites containing $\mathrm{TiO}_{2}$ short nanofibers. Mater Chem Phys 129:701-704

194. Khalil A, Dimas C, Hashaikeh R (2015) Electrospun copper oxide nanofibers as infrared photodetectors. Appl Phys A 118:217-224

195. Zhou X, Qiu Y, Yu J, Yin J, Bai X (2012) High electrochemical activity from hybrid materials of electrospun tungsten oxide nanofibers and carbon black. J Mater Sci 47:6607-6613

196. Katoch A, Choi SW, Kim SS (2015) Nanograins in electrospun oxide nanofibers. Met Mater Int 21:213-221

197. Kim HK, Honda W, Kim BS, Kim IS (2013) Preparation and magnetic properties of electrospun $\mathrm{CuO} / \mathrm{NiO}$ bimetallic nanofibers via sol-gel electrospinning. J Mater Sci 48:1111-1116

198. Ding Y, Wang Y, Su L, Zhang H, Lei Y (2010) Preparation and characterization of $\mathrm{NiO}-\mathrm{Ag}$ nanofibers, $\mathrm{NiO}$ nanofibers, and porous Ag: towards the development of a highly sensitive and selective nonenzymatic glucose sensor. J Mater Chem 20:9918-9926

199. Cao F, Gong J (2012) Nonenzymatic glucose sensor based on $\mathrm{CuO}$ microfibers composed of $\mathrm{CuO}$ nanoparticles. Anal Chim Acta 723:39-44

200. Song Y, Li X, Wei C, Fu J, Xu F, Tan H, Tang J, Wang L (2015) A green strategy to prepare metal oxide superstructure from metalorganic frameworks. Sci Rep 5:8401

201. Zhou C, Xu L, Song J, Xing R, Xu S, Liu D, Song H (2014) Ultrasensitive nonenzymatic glucose sensor based on threedimensional network of $\mathrm{ZnO}-\mathrm{CuO}$ hierarchical nanocomposites by electrospinning. Sci Rep 4:7382

202. Anitha S, Thiruvadigal DJ, Natarajan TS (2011) A study on defect controlled morphology of organic/inorganic composite nanofibers with different heat flow rates. Mater Lett 65:167-170
203. Wang W, Zhang L, Tong S, Li X, Song W (2009) Threedimensional network films of electrospun copper oxide nanofibers for glucose determination. Biosens Bioelectron 25:708-714

204. Liu G, Zheng B, Jiang Y, Cai Y, Du J, Yuan H, Xiao D (2012) Improvement of sensitive $\mathrm{CuO}$ NFs-ITO nonenzymatic glucose sensor based on in situ electrospun fiber. Talanta 101:24-31

205. Pickup JC, Hussain F, Evans ND, Rolinski OJ, Birch DJS (2005) Fluorescence-based glucose sensors. Biosens Bioelectron 20: 2555-2565

206. Xia Y, Ye J, Tan K, Wang J, Yang G (2013) Colorimetric visualization of glucose at the submicromole level in serum by a homogenous silver nanoprism-glucose oxidase system. Anal Chem 85: $6241-6247$

207. Zhao W, Brook MA, Li Y (2008) Design of gold nanoparticlebased colorimetric biosensing assays. Chem Biol Chem 9:23632371

208. Wang XD, Chen HX, Zhou TY, Lin ZJ, Zeng JB, Xie ZX, Chen X, Wong KY, Chen GN, Wang XR (2009) Optical colorimetric sensor strip for direct readout glucose measurement. Biosens Bioelectron 24:3702-3705

209. Xu X, Yang X (2011) Facile colorimetric detection of glucose based on an organic Fenton reaction. Anal Methods 3: $1056-1059$

210. Senthamizhan A, Celebioglu A, Uyar T (2015) Real-time selective visual monitoring of $\mathrm{Hg}^{2+}$ detection at ppt level: an approach to lighting electrospun nanofibers using gold nanoclusters. Sci Rep 5:10403

211. Chen LY, Wang CW, Yuan Z, Chang HT (2015) Fluorescent gold nanoclusters: recent advances in sensing and imaging. Anal Chem 87:216-229

212. Basabe-Desmonts L, Reinhoudt DN, Crego-Calama M (2007) Design of fluorescent materials for chemical sensing. Chem Soc Rev 36:993-1017

213. Song Y, Wei W, Qu X (2011) Colorimetric biosensing using smart materials. Adv Mater 23:4215-4236

214. Costa MN, Veigas B, Jacob JM, Santos DS, Gomes J, Baptista PV, Martins R, Inácio J, Fortunato E (2014) A low cost, safe, disposable, rapid and self-sustainable paper-based platform for diagnostic testing: lab-on-paper. Nanotechnology 25:094006

215. Takatsuji Y, Yamasaki R, Iwanaga A, Lienemann M, Linder MB, Haruyama T (2013) Solid-support immobilization of a "swing" fusion protein for enhanced glucose oxidase catalytic activity. Colloids Surf B: Biointerfaces 112:186-191

216. Snejdárková M, Rehák M, Otto M (1993) Design of a glucose minisensor based on streptavidin-glucose oxidase complex coupling with self-assembled biotinylated phospholipid membrane on solid support. Anal Chem 65:665668

217. Ji X, Su Z, Wang P, Ma G, Zhang S (2014) "Ready-to-use" hollow nanofiber membrane-based glucose testing strips. Analyst 139: 6467-6473

218. Zhou C, Shi Y, Ding X, Li M, Luo J, Lu Z, Xiao D (2013) Development of a fast and sensitive glucose biosensor using iridium complex-doped electrospun optical fibrous membrane. Anal Chem 85:1171-1176

219. Wang J (2008) In vivo glucose monitoring: towards "sense and act" feedback-loop individualized medical systems. Talanta 75: 636-641

220. Pickup JC, Hussain F, Evans ND, Sachedina N (2005) In vivo glucose monitoring: the clinical reality and the promise. Biosens Bioelectron 20:1897-1902

221. Jiang Y, Zhao H, Lin Y, Zhu N, Ma Y, Mao L (2010) Colorimetric detection of glucose in rat brain using gold nanoparticles. Angew Chem Int Ed 49:4800-4804 
222. Shichiri M, Kawamori R, Yamasaki Y, Hakui N, Abe H (1982) Wearable artificial endocrine pancrease with needle-type glucose sensor. Lancet 2:1129-1131

223. Ozaydin-Ince G, Dubach JM, Gleason KK, Clark HA (2011) Microworm optode sensors limit particle diffusion to enable in vivo measurements. Proc Natl Acad Sci U S A 108:2656-2661

224. Pleitez MA, Lieblein T, Bauer A, Hertzberg O, Lilienfeld-Toal HV, Mäntele W (2013) In vivo noninvasive monitoring of glucose concentration in human epidermis by mid-infrared pulsed photoacoustic spectroscopy. Anal Chem 85:1013-1020

225. Nakayama D, Takeoka Y, Watanabe M, Kataoka K (2003) Simple and precise preparation of a porous gel for a colorimetric glucose sensor by a templating technique. Angew Chem Int Ed 42:4197-4200

226. Heo YJ, Shibata H, Okitsu T, Kawanishi T, Takeuchi S (2011) Long-term in vivo glucose monitoring using fluorescent hydrogel fibers. Proc Natl Acad Sci U S A 108:13399-13403

227. Yoon J, Czarnik AW (1992) Fluorescent chemosensors of carbohydrates. A means of chemically communicating the binding of polyols in water based on chelation-enhanced quenching. J Am Chem Soc 114:5874-5875

228. Balaconis MK, Luo Y, Clark HA (2015) Glucose-sensitive nanofiber scaffolds with an improved sensing design for physiological conditions. Analyst 140:716-723 